PROBABILISTIC PERFORMANCE FORECASTING FOR UNCONVENTIONAL RESERVOIRS WITH STRETCHED-EXPONENTIAL MODEL

\author{
A Thesis \\ by \\ BUNYAMIN CAN \\ Submitted to the Office of Graduate Studies of \\ Texas A\&M University \\ in partial fulfillment of the requirements for the degree of \\ MASTER OF SCIENCE
}

May 2011

Major Subject: Petroleum Engineering 
Probabilistic Performance Forecasting for Unconventional Reservoirs with Stretched-

Exponential Model

Copyright 2011 Bunyamin Can 


\title{
PROBABILISTIC PERFORMANCE FORECASTING FOR UNCONVENTIONAL RESERVOIRS WITH STRETCHED-EXPONENTIAL MODEL
}

\author{
A Thesis \\ by \\ BUNYAMIN CAN
}

\begin{abstract}
Submitted to the Office of Graduate Studies of
Texas A\&M University

in partial fulfillment of the requirements for the degree of

MASTER OF SCIENCE
\end{abstract}

\begin{abstract}
Approved by:
Chair of Committee, Peter P. Valko

Committee Members, Walter B. Ayers

Yuefeng Sun

Head of Department, Stephen A. Holditch
\end{abstract}

May 2011

Major Subject: Petroleum Engineering 


\begin{abstract}
Probabilistic Performance Forecasting for Unconventional Reservoirs with StretchedExponential Model.

(May 2011)

Bunyamin Can, B.S., Istanbul Technical University

Chair of Advisory Committee: Dr. Peter P. Valko
\end{abstract}

Reserves estimation in an unconventional-reservoir setting is a daunting task because of geologic uncertainty and complex flow patterns evolving in a long-stimulated horizontal well, among other variables. To tackle this complex problem, we present a reservesevaluation workflow that couples the traditional decline-curve analysis with a probabilistic forecasting frame. The stretched-exponential production decline model (SEPD) underpins the production behavior. Our recovery appraisal workflow has two different applications: forecasting probabilistic future performance of wells that have production history; and forecasting production from new wells without production data. For the new field case, numerical model runs are made in accord with the statistical design of experiments for a range of design variables pertinent to the field of interest. In contrast, for the producing wells the early-time data often need adjustments owing to restimulation, installation of artificial-lift, etc. to focus on the decline trend. Thereafter, production data of either new or existing wells are grouped in accord with initial rates to obtain common SEPD parameters for similar wells. After determining the distribution of 
model parameters using well grouping, the methodology establishes a probabilistic forecast for individual wells.

We present a probabilistic performance forecasting methodology in unconventional reservoirs for wells with and without production history. Unlike other probabilistic forecasting tools, grouping wells with similar production character allows estimation of self-consistent SEPD parameters and alleviates the burden of having to define uncertainties associated with reservoir and well-completion parameters. 


\section{DEDICATION}

This work is dedicated to my family. 


\section{ACKNOWLEDGEMENTS}

I would like to thank my graduate advisor Dr. Peter P. Valko for serving as the chair of my advisory committee, for his guidance, influence and support during the years of my graduate study.

I would like to thank Dr. Walter B. Ayers and Dr. Yuefeng Sun for serving as committee members and Dr. Michael Pope for his helpful comments and suggestions.

My sincere appreciation goes to Shah Kabir and HESS Corporation for providing me the opportunities which enhanced the scope of this research. 


\section{TABLE OF CONTENTS}

Page

ABSTRACT ........................................................................................

DEDICATION ...................................................................................

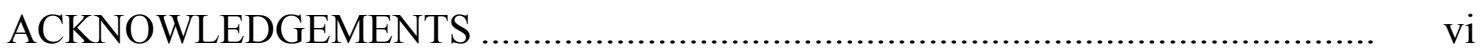

TABLE OF CONTENTS ....................................................................... vii

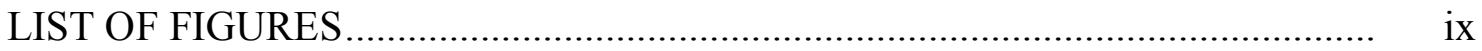

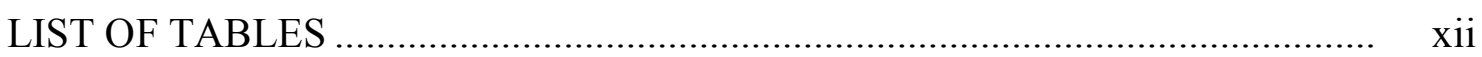

CHAPTER

I INTRODUCTION ............................................................ 1

1.1 Statement of the Problem .................................................... 1

1.2 Objectives .................................................................... 3

II LITERATURE REVIEW ....................................................... 4

2.1 Existing Production Decline Curve Methods ............................ 4

2.2 Modifications to Arps' Hyperbolic Relation ............................. 7

2.3 Probabilistic Reserve Estimation Efforts Using DCA ............. 10

2.4 Statistical Approaches ......................................................... 11

III DEVELOPMENT OF THE PROBABILISTIC RESERVES

ESTIMATE METHOD .............................................................. 13

3.1 The Stretched-Exponential Production Decline Model ............. 13

3.2 Guidelines for Production Data Gathering and Editing ............ 16

3.2.1 Data Generation for New Wells ........................... 17

3.2.2 Data Editing for Existing Wells ........................... 18

3.3 Determining Model Parameters .............................................. 20

3.4 Production Data Grouping - A Parameter Distribution Apparatus ...................................................................... 21 


\section{CHAPTER}

IV APPLICATION OF THE METHOD TO SYNTHETIC AND

FIELD EXAMPLES

4.1 Synthetic Case Demonstration Examples .............................. 24

4.1.1 Synthetic Example 1: Elm Coulee Oil Field .......... 24

4.1.2 Synthetic Example 2: Marcellus Gas Field ............ 26

4.2 Field Case Demonstration Examples ..................................... 28

4.2.1 Field Example 2: Barnett Gas Field ...................... 28

4.2.2 Field Example 2: Marcellus Gas Field ................. 35

4.2.3 Field Example 3: Elm Coulee Oil Field ................. 43

4.2.4 Overall Results.................................................. 49

V SUMMARY, CONCLUSIONS, AND RECOMMENDATIONS ..... 51

5.1 Summary ................................................................... 51

5.2 Conclusions ................................................................... 52

5.3 Recommendations ............................................................ 53

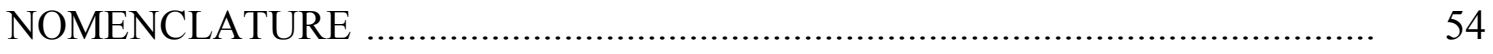

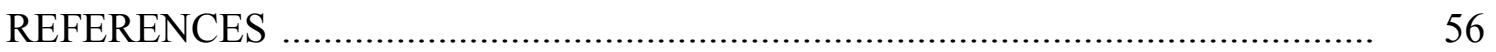

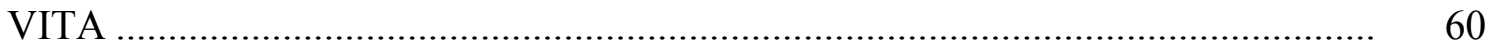




\section{LIST OF FIGURES}

FIGURE Page

3.1 Comparison of SEPD and Arps decline relations ................................ 15

3.2 Estimating recovery potential with SEPD model ................................. 16

3.3 Pareto chart of standardized effects of variables on 30-year cumulative production

3.4 Fitting the dominant production-decline behavior to obtain SEPD parameters

3.5 Procedure for obtaining model parameters, $\mathrm{n}$ and $\tau$

3.6 Fitting the dominant production-decline behavior to obtain SEPD parameters.

4.1 Synthetic oil case - Production forecast up to 40 years of one of the wells

4.2 Estimates and actual recovery of 27 wells after 40 years of history in synthetic oil field

4.3 Estimates and actual recovery of 27 wells after 30 years of history in synthetic gas field

4.4 Grouping of Barnett Shale wells based on their peak production

4.5 Distribution of $\mathrm{n}$ and $\tau$ parameter pairs of Barnett Shale gas field example.

4.6 Monthly production history plot for first field example of Barnett Shale 
FIGURE Page

4.7 Actual and estimated production decline of first field example in Barnett Shale

4.8 Recovery potential plot of first field example in Barnett Shale

4.9 Monthly production history plot for second field example of Barnett Shale

4.10 Production forecast of the second field example in Barnett Shale

4.11 Estimates and actual recovery of 40 wells in Barnett Shale gas play

4.12 Grouping of Barnett Shale wells based on their peak production

4.13 Distribution of $\mathrm{n}$ and $\tau$ parameter pairs of Marcellus Shale gas field example

4.14 Monthly production history plot for first field example of Marcellus Shale

4.15 Production forecast of the first field example in Marcellus Shale

4.16 Recovery potential plot of the second field example in Marcellus Shale

4.17 Monthly production history plot for second field example of Barnett Shale

4.18 Production forecast of the second field example in Marcellus Shale

4.19 Recovery potential plot of the second field example in Marcellus Shale

4.20 Estimates and actual cumulative production of 40 wells in Marcellus Shale gas play 
FIGURE Page

4.21 Grouping of Elm Coulee oil field wells based on their peak production .......................................................................... 44

4.22 Distribution of $\mathrm{n}$ and $\tau$ parameter pairs of Elm Coulee oil field example............................................................................... 45

4.23 Monthly production history plot for field example of Elm Coulee oil field

4.24 Production forecast of the field example in Elm Coulee oil field

4.25 Recovery potential plot of the field example in Elm Coulee oil field 48

4.26 Estimates and actual cumulative production of 40 wells in Elm Coulee oil field 


\section{LIST OF TABLES}

TABLE $\quad$ Page

2.1 Decline curve methods in the literature................................................. 4

2.2 Various modifications to Arps' hyperbolic relation .............................. 7

2.3 Various probabilistic reserve estimation methods using DCA …............ 10

3.1 SEPD model and Arps' hyperbolic family of relations ........................... 14

3.2 Range of parameter values that have significant impact on production ......................................................................................... 18

4.1 Common $\mathrm{n}$ and $\tau$ parameters for synthetic Elm Coulee oil field ............. 25

4.2 Common $\mathrm{n}$ and $\tau$ parameters for synthetic Marcellus gas field ................ 27

4.3 Percentage of wells fall within and outside the P10 - P90 range ............ 50 


\section{CHAPTER I}

\section{INTRODUCTION}

\subsection{Statement of the Problem}

Since the initiation of the oil industry, reserve estimation efforts have been carried on continuously. Decline curve analysis (DCA) methods have been generally empirical and interpretations are results of the experience and objectives of the evaluator. Since the publication of Arps' decline curve relations (Arps 1956), reserve estimation has been primarily performed using his methods. Fetkovich's works $(1980,1987)$ brought a better understanding and tried to add an analytical meaning to the problem. These approaches seemed to satisfy the industry until unconventional reservoir systems became a significant potential of reserves growth and future production. Tight gas sands, shale gas, tight/shale oil and coalbed methane reservoirs are currently being pursued for new development in the US. These reservoirs are difficult to characterize and produce because of their ultra-low permeability. Special well stimulation operations (e.g., single or multi-stage hydraulic fracturing, etc.) are required to produce these reservoirs. Most of the production data from ultra-low permeability reservoirs do not reach late-time flow regimes (e.g., pseudosteady-state, etc.) even after several years of production.

This thesis follows the style of SPE Journal 
Despite of the common belief in the oil industry that Arps' rate-time relations (specifically hyperbolic relation) do not work for ultra-low permeability reservoirs where fracture flow is dominant, this reality does not retain engineers to use Arps' relations to estimate future performance of wells producing from unconventional reservoirs. This is due to the straightforward nature of the methodology, the few required elements (i.e., past production data), and lack of alternative solutions to the problem.

Traditionally, DCA methods were considered as deterministic tools without offering an understanding to uncertainty. Often, however, outcome is far from representing the actual trend and leads to significant errors in reserve estimation. Probabilistic approaches, on the other hand, offer a measure of uncertainty and attempt to bracket the true value within a range of estimates. Recently, a lot of effort has been put to create a consistent probabilistic approach evaluating uncertainty in reserve estimates based on DCA.

Valko (2009) developed a decline model called Stretched-Exponential Decline Model, (SEDM), which addresses the problem of handling unconventional reservoir behavior. The two most significant advantages of the new approach are the bounded nature of estimated ultimate recovery (EUR) without limits on time or rate, and the straight-line behavior of a recovery potential expression (Valko and Lee 2010). Our experiences showed that in tight formations where transient flow period is extremely long, SEDM has been successful in modeling the rate-time behavior and provides more realistic reserve estimates compared to Arps' decline relations. 
Valko and Lee (2010) developed a new methodology called "group-data controlled forecast." This methodology suggests taking advantage of enormous quantity of data which is publicly available. This approach provides opportunity to run algorithms on huge samples and evaluate statistics. Combining SEDM and so called 'data-intensive discovery', the authors provide a controlled production forecast for wells which belong to a large group of wells. Study also provides a probabilistic reserve estimate concept. In this study we present a probabilistic performance forecasting method for unconventional reservoirs using SEDM as a reliable approach to reserve estimation. This method provides a diagnostic tool to predict probabilistic future performance and reserve estimates.

\subsection{Objectives}

The objectives of this work are to:

- Analyze applicability and accuracy of SEDM when dealing with large datasets;

- Develop a consistent methodology for probabilistic quantification of reserve estimate using SEDM and large datasets;

- Validate the proposed methodology using synthetic data and perform verification by incorporating sufficient data from unconventional oil and gas wells. 


\section{CHAPTER II}

\section{LITERATURE REVIEW}

Examining well behavior and predicting future performance is a common practice since the beginning of the industry. The scope of this section is to provide a general overview of existing production decline curve analysis methods.

\subsection{Existing Production Decline Curve Methods}

This section briefly describes various decline curve methods in a digest form.

Table 2.1 - Decline curve methods in the literature.

\begin{tabular}{|c|c|}
\hline Authors & Contribution \\
\hline $\begin{array}{l}\text { Lewis and Beal } \\
\text { (1918) }\end{array}$ & $\begin{array}{l}\text { Decline curve used first time as a systematic production } \\
\text { forecasting tool. } \\
\text { Power-law behavior of production decline identified. } \\
\text { Introduce the law of equal expectations. }\end{array}$ \\
\hline $\begin{array}{l}\text { Johnson and Bollens } \\
\text { (1927) }\end{array}$ & $\begin{array}{l}\text { - Adapted the power-law curve-fitting to a table form in } \\
\text { order to get rid of the burden of graphical approach. } \\
\text { Introduced the loss ratio relation; } \\
\quad \frac{1}{D_{i}} \cong-\frac{q}{d q d t} \ldots \ldots \ldots \ldots \ldots \ldots \ldots \ldots \ldots \ldots \ldots \ldots \ldots \ldots \ldots \ldots \\
\text { Assumed a constant loss ratio which yields the } \\
\text { exponential decline. }\end{array}$ \\
\hline Gross (1939) & $\begin{array}{l}\text { Investigated two types of decline curve; } \\
\text { - Semi-log decline curve } \\
\text { - Percentage of oil in the fluid versus cumulative } \\
\text { production (Cartesian) } \\
\text { Concluded that second method produces more accurate } \\
\text { results. }\end{array}$ \\
\hline
\end{tabular}




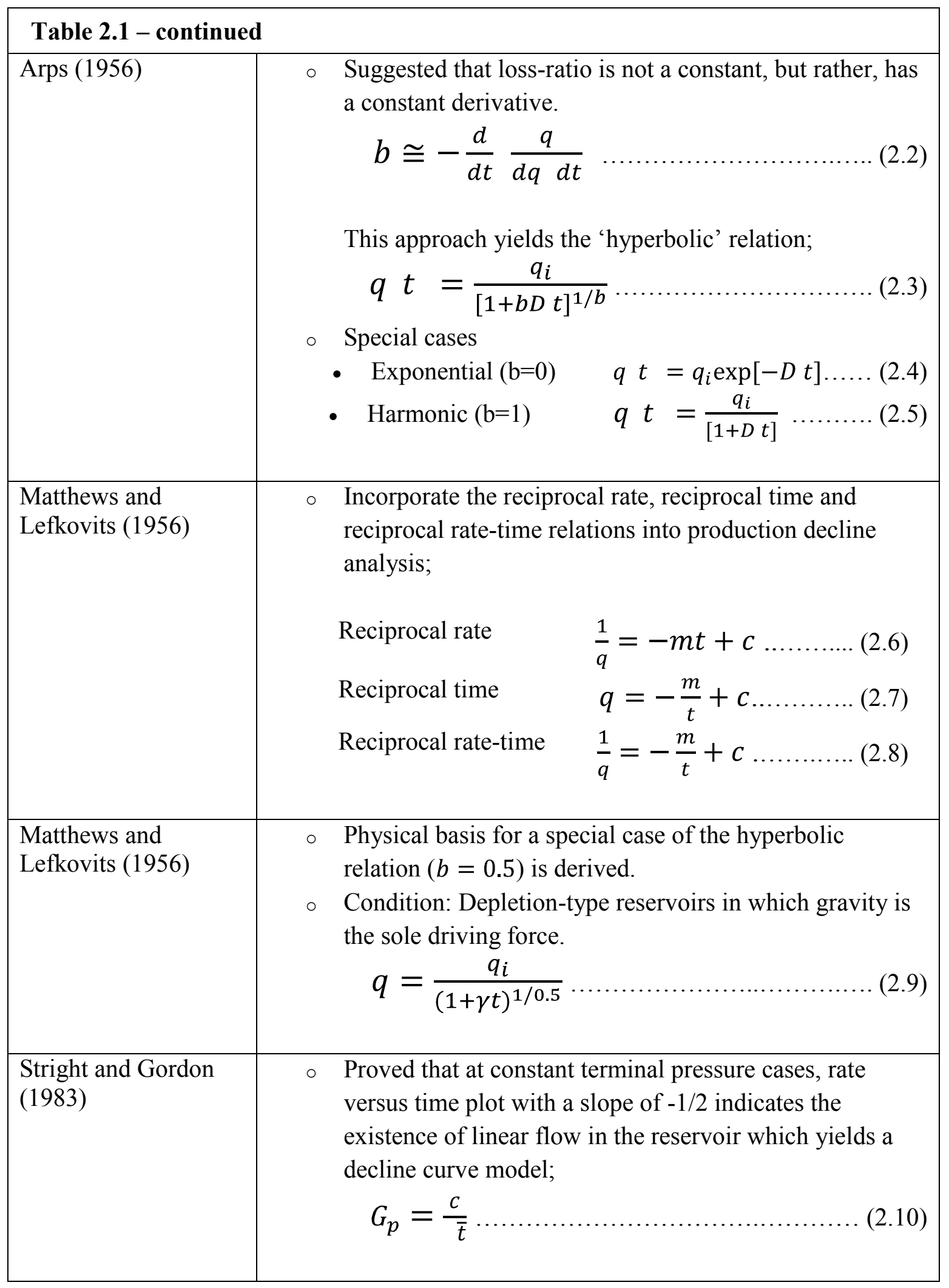




\begin{tabular}{|c|c|c|}
\hline \multicolumn{3}{|c|}{ Table 2.1 - continued } \\
\hline Chen (1991) & $\circ$ & $\begin{array}{l}\text { Derived a new decline curve method; } \\
G_{p}=\frac{q_{i}}{D_{i}} \frac{1}{1-n}+\frac{1}{D_{i}} \frac{1}{n-1} q+\frac{n}{n-1} q t \ldots \ldots(2.11) \\
\text { Discussed that in Russia a decline curve model }- \text { and its } \\
\text { modified form }- \text { generated by Kopatov, is widely used; } \\
G_{p}=a-\frac{b}{\bar{t}} \ldots \ldots \ldots \ldots \ldots \ldots \ldots \ldots \ldots \ldots \ldots \ldots \ldots \ldots \ldots \ldots \ldots \ldots \ldots \ldots \ldots \ldots \ldots \ldots \ldots \ldots \ldots \ldots \ldots \ldots \ldots \ldots \ldots\end{array}$ \\
\hline $\begin{array}{l}\text { Blasingame and } \\
\text { Rushing (2005) }\end{array}$ & $\circ$ & $\begin{array}{l}\text { Derived a new decline curve model from the basis of the } \\
\text { gas material balance equation for a volumetric dry gas } \\
\text { well producing at a constant bottomhole pressure; } \\
q_{g}=q_{q i}-D_{i} G_{p}+\frac{1}{2} \frac{D_{i}}{G} G_{p}^{2} \ldots \ldots \ldots \ldots \ldots \ldots \ldots(2.14) \\
\text { where } \\
\qquad D_{i}=\frac{2 q_{g i}}{p_{w f} z_{w f}} \ldots \ldots \ldots \ldots \ldots \ldots \ldots \ldots \ldots \ldots \ldots \\
1-\frac{p_{i} z_{i}}{}\end{array}$ \\
\hline Ilk et al (2008) & ○ & $\begin{array}{l}\text { Introduced a new decline model for tight gas sands what } \\
\text { is called power law exponential rate decline. } \\
\qquad q=q_{i} \exp -D_{\infty} t-\frac{D_{1}}{n} t^{n} \ldots \ldots \ldots \ldots \ldots \ldots \text { (2.16) } \\
\text { where } \\
q_{i}=\text { Rate intercept } \\
D_{1}=\text { Decline constant intercept at } 1 \text { time unit } \\
D_{\infty}=\text { Decline constant at infinite time } \\
n=\text { Time exponent }\end{array}$ \\
\hline
\end{tabular}


Table 2.1 - continued

Shirman (1999)

- Suggested a loss-ratio model which is approximated by a power function;

$$
D=a q^{n}=-\frac{1}{q} \frac{d q}{d t}
$$

which yields a linear rate-time relation in log-log coordinates.

$$
\ln a+n+1 \ln q=\ln -\frac{d q}{d t}
$$

As it is seen from Table 2.1, a lot of effort spent on loss-ratio analysis. Aside from plain relations (e.g. semi-log straight-line decline, reciprocal rate decline), there is an agreement in the literature on the value of loss-ratio concept. While the definition of loss-ratio has remained essentially same, scholars have extended the use of the concept.

\subsection{Modifications to Arps' Hyperbolic Relation}

This section outlines the efforts to modify and improve Arps' hyperbolic relation.

\begin{tabular}{|c|c|c|}
\hline Authors & & Contribution \\
\hline Mead (1956) & ० & $\begin{array}{l}\text { Modified Arps' loss-ratio concept. Developed a finite } \\
\text { difference equation of production for equal time intervals } \\
\text { instead of a continuous function of production rate with } \\
\text { time as Arps suggested. } \\
\text { Presented various b values for various types of reservoir } \\
\text { drive mechanisms. }\end{array}$ \\
\hline $\begin{array}{l}\text { Shea and Higgins } \\
\text { (1964) }\end{array}$ & ○ & $\begin{array}{l}\text { Compared linear, semi-log, log-log and hyperbolic } \\
\text { relations and claimed that hyperbolic relation delivers the } \\
\text { best results. }\end{array}$ \\
\hline
\end{tabular}

Table 1.2 - Various modifications to Arps' hyperbolic relation. 


\begin{tabular}{|c|c|c|}
\hline \multicolumn{3}{|c|}{ Table 2.2 - continued } \\
\hline Slider (1968) & ० & $\begin{array}{l}\text { Proposed a method for analyzing hyperbolic decline } \\
\text { curve constants using transparent overlays. }\end{array}$ \\
\hline $\begin{array}{l}\text { Higgins and } \\
\text { Lechtenberg (1969) }\end{array}$ & ○ & $\begin{array}{l}\text { Proposed a new method modified from the hyperbolic } \\
\text { relation which is called 'extreme-C'; } \\
\qquad q=\frac{q_{i}}{(1+c t)^{h}} \ldots \ldots \ldots \ldots \ldots \ldots \ldots \ldots \ldots \ldots \ldots \ldots \ldots \ldots \\
\text { where; } \\
c=0.1 \text { or } 10 \text { depending on the production data } \\
h \text { and } q_{i} \text { are determined from regression. }\end{array}$ \\
\hline Stewart (1970) & & $\begin{array}{l}\text { Proved that for wells flowing at constant terminal } \\
\text { pressure final production decline is exponential. }\end{array}$ \\
\hline Gentry (1972) & & $\begin{array}{l}\text { Generated dimensionless semi-log rate-time/rate- } \\
\text { cumulative production decline type curves. }\end{array}$ \\
\hline Fetkovich (1980) & & $\begin{array}{l}\text { Generated dimensionless log-log type curves for } \\
\text { exponential and hyperbolic relations. } \\
\text { Attempted to derive connections between decline } \\
\text { constants and reservoir and fluid characteristics using } \\
\text { material balance equation, rate equation, etc. }\end{array}$ \\
\hline $\begin{array}{l}\text { Gentry and McCray } \\
\text { (1978) }\end{array}$ & & $\begin{array}{l}\text { Investigate the situations which result a b exponent } \\
\text { greater than unity. Numerical simulation study showed } \\
\text { that reservoir heterogeneity can cause this type of } \\
\text { production decline. }\end{array}$ \\
\hline $\begin{array}{l}\text { McNulty and Knapp } \\
\text { (1981) }\end{array}$ & & $\begin{array}{l}\text { Used computer-aided non-linear regression methods first } \\
\text { time to find the best values of hyperbolic relation } \\
\text { parameters. }\end{array}$ \\
\hline Luther (1985) & & 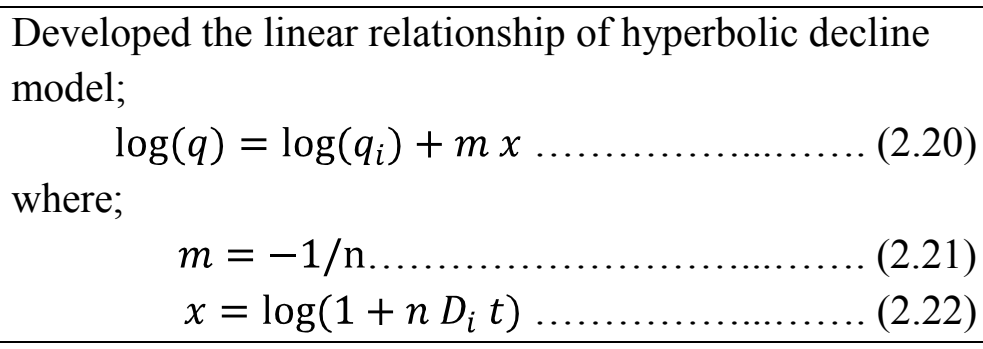 \\
\hline
\end{tabular}




\begin{tabular}{|c|c|}
\hline \multicolumn{2}{|c|}{ Table 2.2 - continued } \\
\hline Maley (1985) & $\begin{array}{l}\text { Through examining field examples, showed that b } \\
\text { exponent often exceeds unity in the case of tight gas } \\
\text { wells and other wells which exhibit linear flow in the } \\
\text { reservoir. }\end{array}$ \\
\hline Agbi and $\mathrm{Ng}$ (1987) & 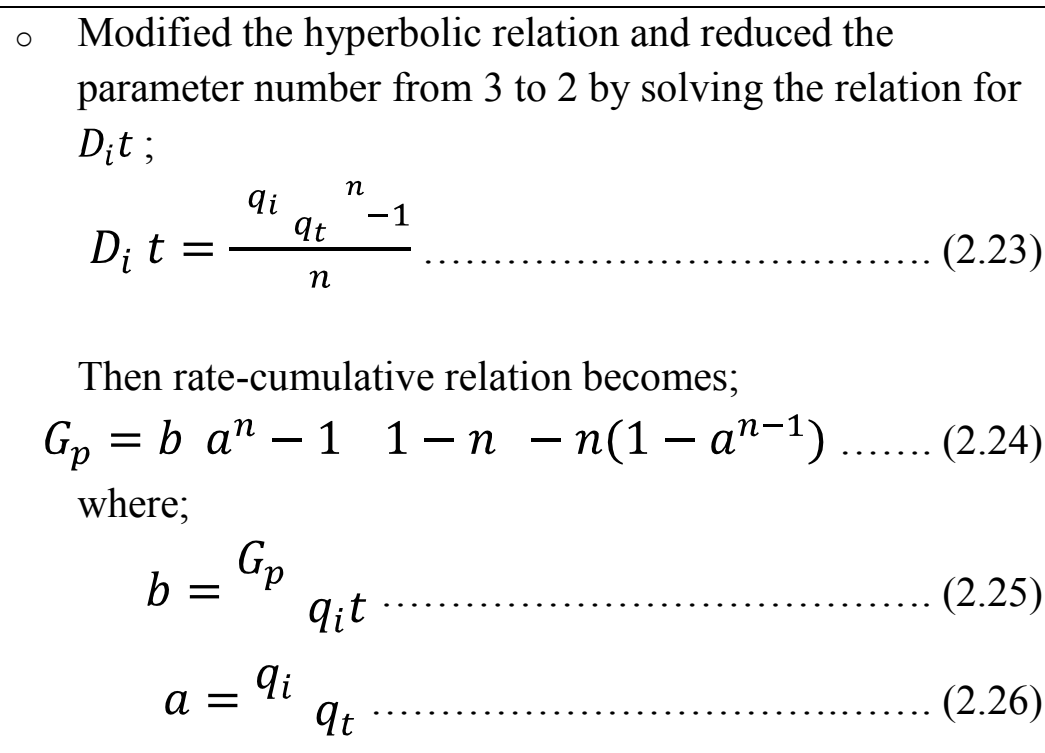 \\
\hline Robertson (1988) & $\begin{array}{l}\text { Suggested a method to overcome the unrealistically high } \\
\text { reserve estimates by changing the decline model from } \\
\text { hyperbolic to constant percentage decline after a } \\
\text { predetermined decline value. }\end{array}$ \\
\hline $\begin{array}{l}\text { Long and Davis } \\
\text { (1988) }\end{array}$ & $\begin{array}{l}\text { Generated dimensionless semi-log type curves similar to } \\
\text { Fetkovich (1973) with a broader range of b exponent; } 0.3 \\
>b>1.7 \text {. } \\
\text { Claimed that a b exponent of } 1.7 \text { is the highest that } \\
\text { commonly occurs based on experience and observation. } \\
\text { For b values exceed unity, the method suggested by } \\
\text { Robertson (1988) is used. }\end{array}$ \\
\hline
\end{tabular}


Table 2.2 shows that most of the past effort was spent on parameter determination work (e.g. logarithm tables, type curves and computer-aided regression methods). Also, possible connections between decline parameters and reservoir and fluid characteristics have investigated in great detail. On the other hand, some scholars pointed out the unrealistically optimistic nature of hyperbolic decline relation.

\subsection{Probabilistic Reserve Estimation Efforts Using DCA}

The historic analysis of production has usually used a deterministic approach in the form of DCA (Idrobo, Jimenez, and Bernal 2001), however estimation of probabilistic distribution of reserves are gaining more and more acceptance in the oil industry. This section describes the notable attempts at probabilistic estimation of reserve using decline curve analysis methods.

Table 2.2 - Various probabilistic reserve estimation methods using DCA.

\begin{tabular}{|l|ll|}
\hline $\begin{array}{l}\text { Hefner and } \\
\text { Thompson (1996) }\end{array}$ & $\circ \begin{array}{l}\text { Published a multiple evaluator comparisons of both } \\
\text { deterministic and probabilistic reserve estimates. } \\
\end{array}$ & $\begin{array}{l}\text { Estimates of evaluators were subjective rather than } \\
\text { statistical approaches. }\end{array}$ \\
& $\circ$ & All evaluators used hyperbolic relations. \\
\hline $\begin{array}{l}\text { Huffman and } \\
\text { Thompson (1994) }\end{array}$ & $\circ \begin{array}{l}\text { Proposed a computational probable reserve estimates } \\
\text { method rather than subjective approaches. } \\
\text { Mochen and Spivey } \\
\text { (1996) }\end{array}$ & $\circ \begin{array}{l}\text { Method incorporates Student's t distribution to predict } \\
\text { the interval. }\end{array}$ \\
& $\circ \begin{array}{l}\text { Used statistical bootstrap method of Monte Carlo } \\
\text { analysis to obtain probabilistic distribution of reserve } \\
\text { estimates. } \\
\text { Method estimates distributions of hyperbolic relation } \\
\text { parameters. }\end{array}$ \\
\hline
\end{tabular}


Table 2.3 - continued

Cheng et al (2005)

- Modified Jochen and Spivey's (1996) work by

incorporating a method called backwards analysis

scheme which uses most recent data for regression

instead of taking all available data into account.

\subsection{Statistical Approaches}

With the emergence of problems involving many particles, classical mechanics study, which means the study of systems of ordinary differential equations, became insufficient. For this kind of systems, the method of statistical mechanics was used. Instead of concentrating on the individual particles, statistical approach studies the properties of sets of particles (Metropolis and Ulam 1949). It is obvious that modeling reservoir performance involves many independent parameters with great uncertainties. Necessity of decision and risk integration into the engineering and economic applications in the oil and gas industry requires bringing statistical design techniques in the reservoir studies as an optimization methodology.

In a risk methodology, it is possible to combine the geological uncertainties by using the Monte Carlo technique to estimate the range of uncertainty of some objective functions (Risso and Schiozer 2007). The Monte Carlo method is generally defined as representing the solution of a problem as a parameter of a hypothetical population, and using a random sequence of numbers to construct a sample of the population, from which statistical estimates of the parameter can be obtained (Halton 1970). Practically, The 
method provides the distribution of the dependent variable based on the distributions of independent variables (i.e., parameters used in the model).

After computers were used widely, Monte Carlo simulation methods gained acceptance by engineers, geoscientists, and other professionals who want to evaluate prospects or to otherwise analyze problems that involve uncertainty (Murtha 1994). Nowadays, among the common applications of Monte Carlo simulation are performance prediction, uncertainty modeling, sensitivity studies, upscaling, history matching, and development optimization.

In the light of the innovations described in Table 2.3, a plethora of publications (e.g., Behrenbruch, Turner, and Backhouse 1985; Patricelli and McMichael 1994) proposed probabilistic methodologies to calculate reserves. In our case we use the sets of reservoir and well parameters information provided by analogs to estimate the production decline behavior of wells without history by performing a Monte Carlo simulation. 


\section{CHAPTER III}

\section{DEVELOPMENT OF THE PROBABILSTIC RESERVES ESTIMATE METHOD}

\subsection{The Stretched-Exponential Production Decline Model}

Stretched-exponential production decline model (Valko 2009) is a performance prediction tool with an intuitive physical basis. Johnston (2006) defines stretchedexponential decay - which was first described by Kohlrausch in 1847 - as a quantity which is generated by a sum of pure exponential decays with a "fat-tailed" probability distribution of the time constant. Valko and Lee (2010) point out that this characteristic of the model can be interpreted as the acknowledgement of the heterogeneity. In particular, the actual production decline is determined by a great number of contributing volumes individually in exponential decay (i.e., in some kind of pseudosteady state), but with a specific distribution of characteristic time constants. The distribution is determined by a parameter pair, $(n, \tau)$ (Valko and Lee, 2010). Table 3.1 shows the SEPD and Arps' hyperbolic family of relations. Note that parameter $n$ in the SEPD model plays somewhat similar role to the $b$ parameter in Arps relations. 
Table 3.1 - SEPD model and Arps' hyperbolic family of relations.

$$
\begin{aligned}
& \text { Rate Relation } \\
& \text { Rate-Cumulative } \\
& \text { Relation } \\
& \quad N_{p, \infty}=\lim _{t \rightarrow \infty} Q \\
& \text { Recovery Potential } \\
& \quad r p=\left(1-\frac{Q}{E U R}\right)
\end{aligned}
$$

Rate Relation

Rate-Cumulative

Relation

$$
N_{p, \infty}=\lim _{t \rightarrow \infty} Q
$$

Recovery Potential

$$
r p=\left(1-\frac{Q}{E U R}\right)
$$

Stretched-Exponential Decline Model Relations

$$
\begin{aligned}
& q=q_{0} \exp -\frac{t}{\tau}^{n} \ldots \ldots \ldots \ldots . . \\
& Q=\frac{q_{0} \tau}{n} \Gamma \frac{1}{\mathrm{n}}-\Gamma \frac{1}{\mathrm{n}}, \frac{t}{\tau}^{n} \\
& N_{p, \infty}=\frac{q_{0} \tau}{n} \Gamma \frac{1}{\mathrm{n}} \ldots \ldots \ldots \ldots \ldots \ldots \\
& r p=\frac{1}{\Gamma \frac{1}{\mathrm{n}}} \Gamma \frac{1}{\mathrm{n}}, \ln \frac{q}{q_{0}} \ldots \ldots \ldots
\end{aligned}
$$

Arps' Hyperbolic Decline Relations

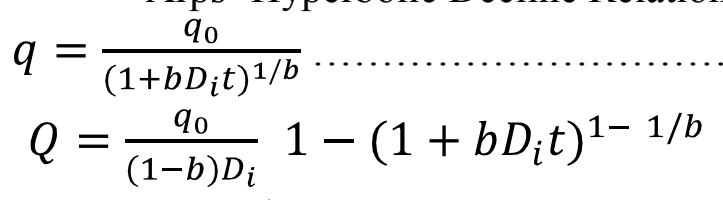

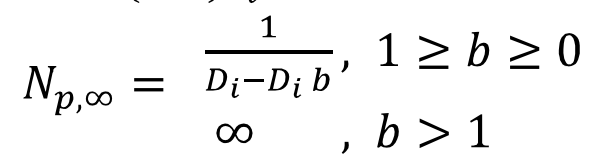

$$
r p={\frac{q}{q_{0}}}^{1-b}, \quad \begin{aligned}
& 1 \geq b \geq 0 \\
& 1,
\end{aligned}
$$

Compared to the Arps formulation, the SEPD offers numerous advantages, which include the bounded nature of estimated ultimate recovery (EUR) from any individual well and the straight-line behavior of recovery potential, or $r p$ expression, versus cumulative production (Valko and Lee 2010). Exponential decline implies the steepest depletion rate of a well in a volumetric system, and is based in analytical roots. As mentioned in the literature review section, Stewart (1970) proved that, for wells flowing at constant terminal pressure, final production decline is exponential. In the Arps formulation, exponential decline is represented by setting $b$ equal to zero. With increasingly large fractional values of $b$, the rate of depletion becomes slower. However, 
when $b$ assumes a value greater than one, nonphysical solutions may result. In other words, the EUR becomes infinitely large, as shown in Table 3.1. This inconvenience is overcome with the bounded nature of SEPD. For instance, the $n$ parameter assumes a value between zero and one for all possible depletion rates. In contrast to the Arps formulation, the exponential decline is represented by setting $n$ equal to one in the SEPD. As depletion gets slower, $n$ assumes smaller values. This phonemenon is explained in Fig. 3.1. As shown in the figure, the exponential decline curves are identical; however, when the depletion rate is slower the Arps' formulation generates a curve with an infinite cumulative production. Conversely, although SEPD yields a decline behavior similar to hyperbolic relation at early times, its behavior at late times reveals its bounded nature.

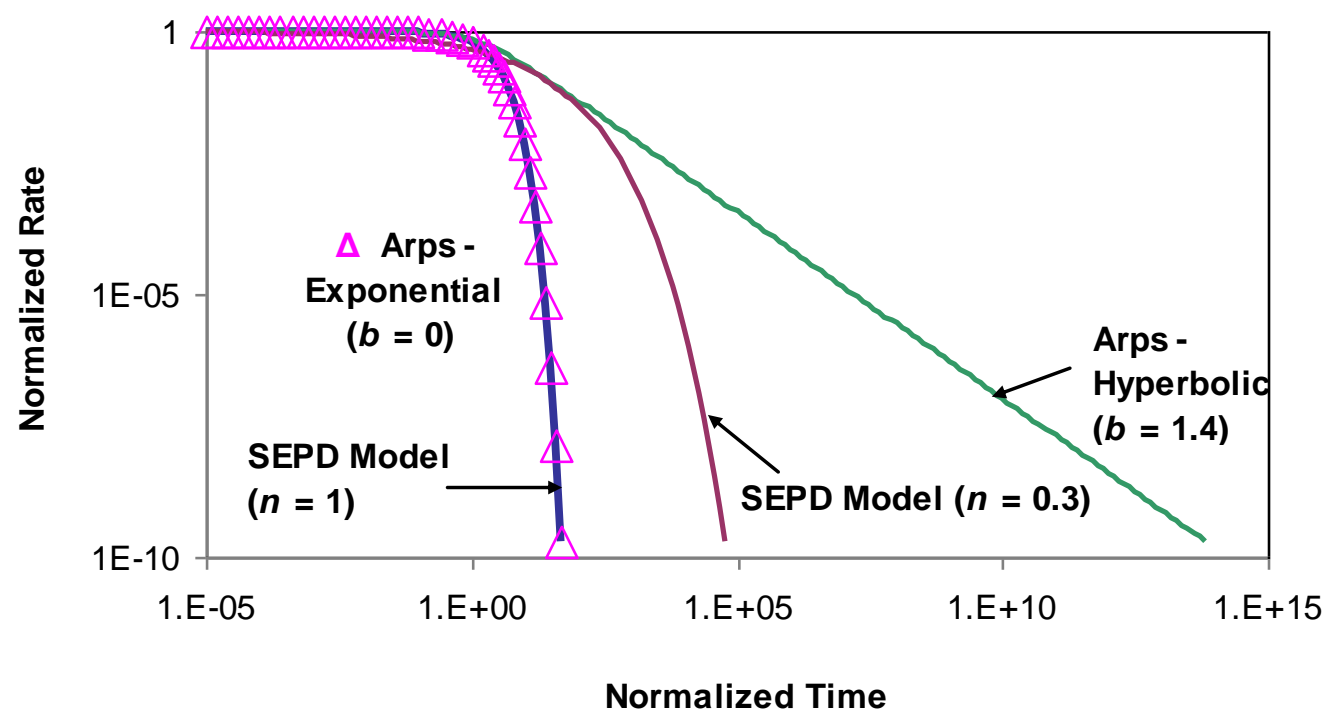

Figure 3.1 - Comparison of SEPD and Arps decline relations. 
The other advantage of SEPD is its ability to construct a straight-line plot of percentage of hydrocarbon recovery potential $(r p)$ versus cumulative production. Fig. 3.2 illustrates the $r p$ plot for the above example. Note that the RF plot cannot be generated with the Arps formulation when $b$ is larger than one because the area under the curve is infinitely large, as indicated in Fig. 3.1.

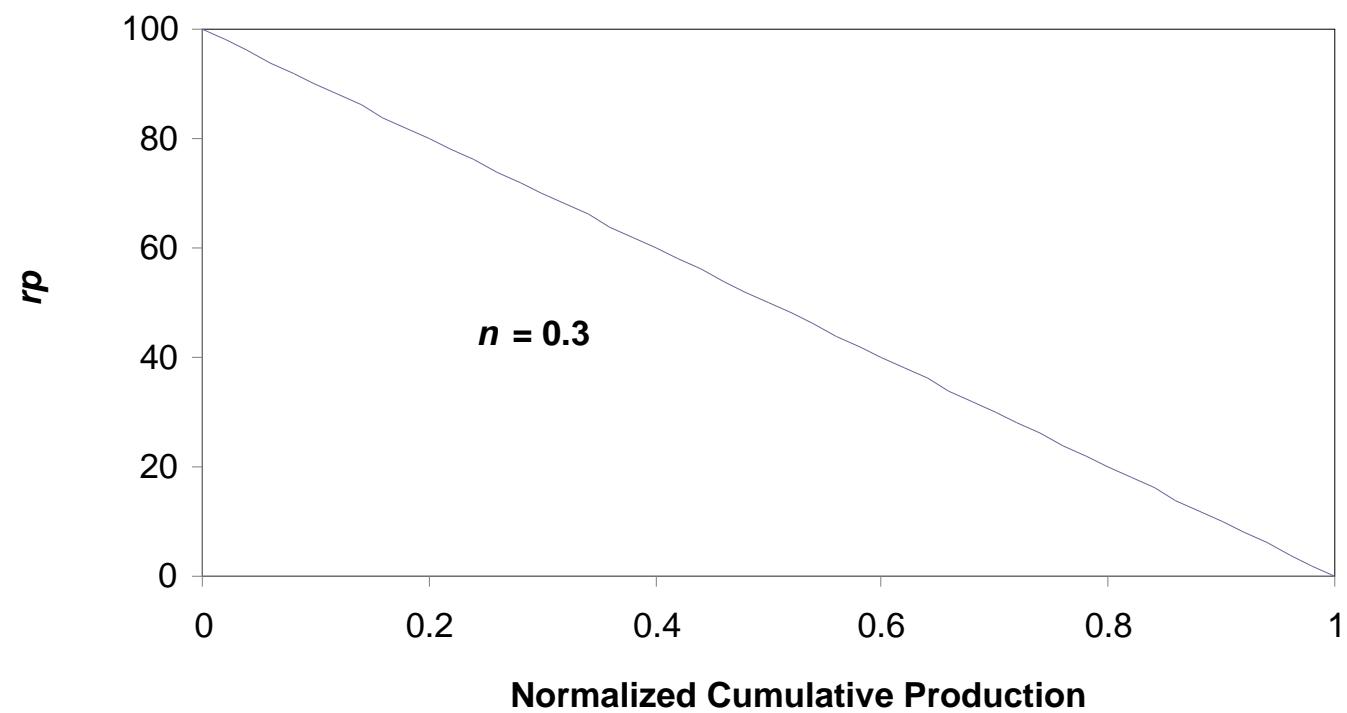

Figure 3.2 - Estimating recovery potential with SEPD model.

\subsection{Guidelines for Production Data Gathering and Editing}

The proposed methodology has two different applications: forecasting future performance of wells that have production history and new wells with no production data. 


\subsubsection{Data Generation for New Wells}

For the new field case, the first step involves data generation. The key parameters with the highest impact on the production history are identified before running essential flow simulations. For this purpose we use the well-known 'Pareto chart' analysis which is a statistical tool used to highlight the most important components among a set of factors. We consider a horizontal well with multiple transverse fractures in a tight reservoir as a base model in order to do initial runs for generating the Pareto chart. Resulting Pareto Chart, which is shown in Fig. 3.3, indicates that production history is sensitive to only four variables; reservoir-flow capacity or $k h$, lateral well length or $L_{w}$, number of stages of transverse fractures, $N_{F S}$, and fracture half-length, $x_{f}$. Fig. 3.3 illustrates the five significant variables and their impact on the Pareto chart. Obviously, the fracture conductivity, $F_{c}$, does not play as big a role as expected, unlike others.

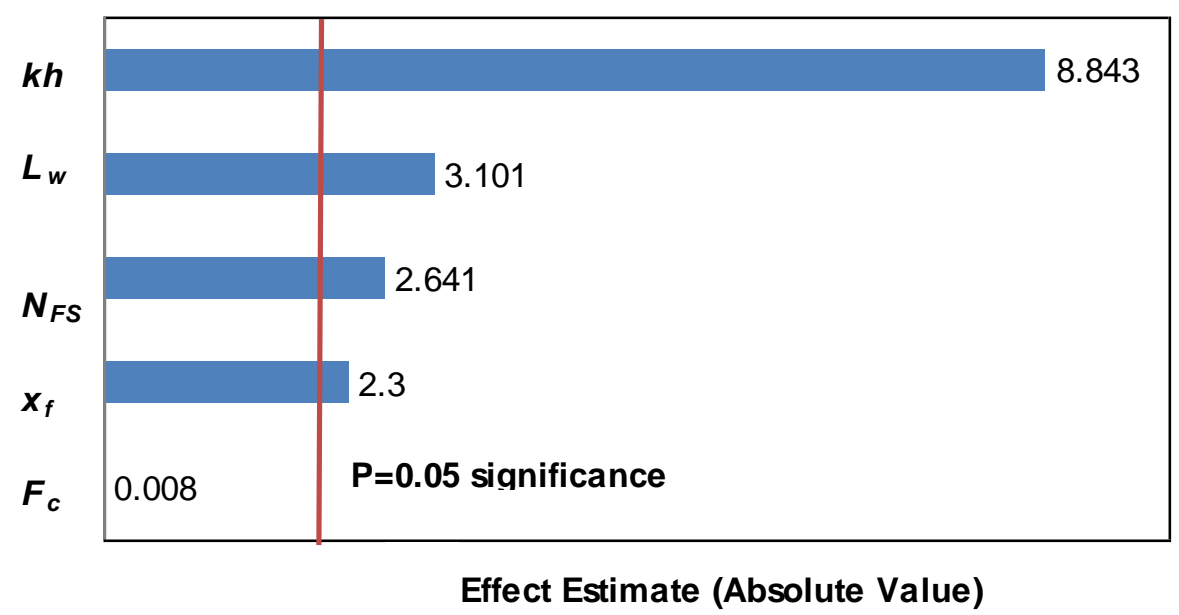

Figure 3.3 - Pareto chart of standardized effects of variables on 30-year cumulative production. 
Proper sets of reservoir and well parameters with realistic ranges are introduced at this stage of the process. The preferred approach for range selection involves investigating seismic data, log, core and well-test data from exploration and appraisal wells and geological knowledge of the region or from analogs. For our study, we selected a nominal well length of $10,560 \mathrm{ft}$ with variable fracture half-length to accommodate changing formation thickness, formation conductivity, and the number of transverse fractures. Table 3.2 summarizes the range of variables selected for a possible new oil field. After that we generate multiple synthetic datasets with a full-factorial design of experiments.

Table 3.2 - Range of parameter values that have significant impact on production.

\begin{tabular}{|l|c|c|c|}
\hline \multicolumn{1}{|c|}{ Properties } & Low & Med. & High \\
\hline$k h, \mathrm{md}-\mathrm{ft}$ & 0.1 & 0.6 & 3 \\
\hline Frac. Half-Length, $\mathrm{ft}$ & 250 & 350 & 450 \\
\hline Number of Fracture Stages & 3 & 7 & 10 \\
\hline
\end{tabular}

\subsubsection{Data Editing for Existing Wells}

For the existing well case, production data of individual wells is monitored. As mentioned earlier, novel restimulation technology of multiple hydraulic fracturing in tight gas and oil reservoirs, dramatically changes the decline trend of the existed wells. This technology was utilized widely in Barnett Shale and resulted in an inconsistent production decline behavior as shown in Fig. 3.4. In this study, only the dominant 
decline trend is used for curve-fitting purposes for mentioned irregular decline behaviors. In such cases early production data are added to the EUR as a constant.

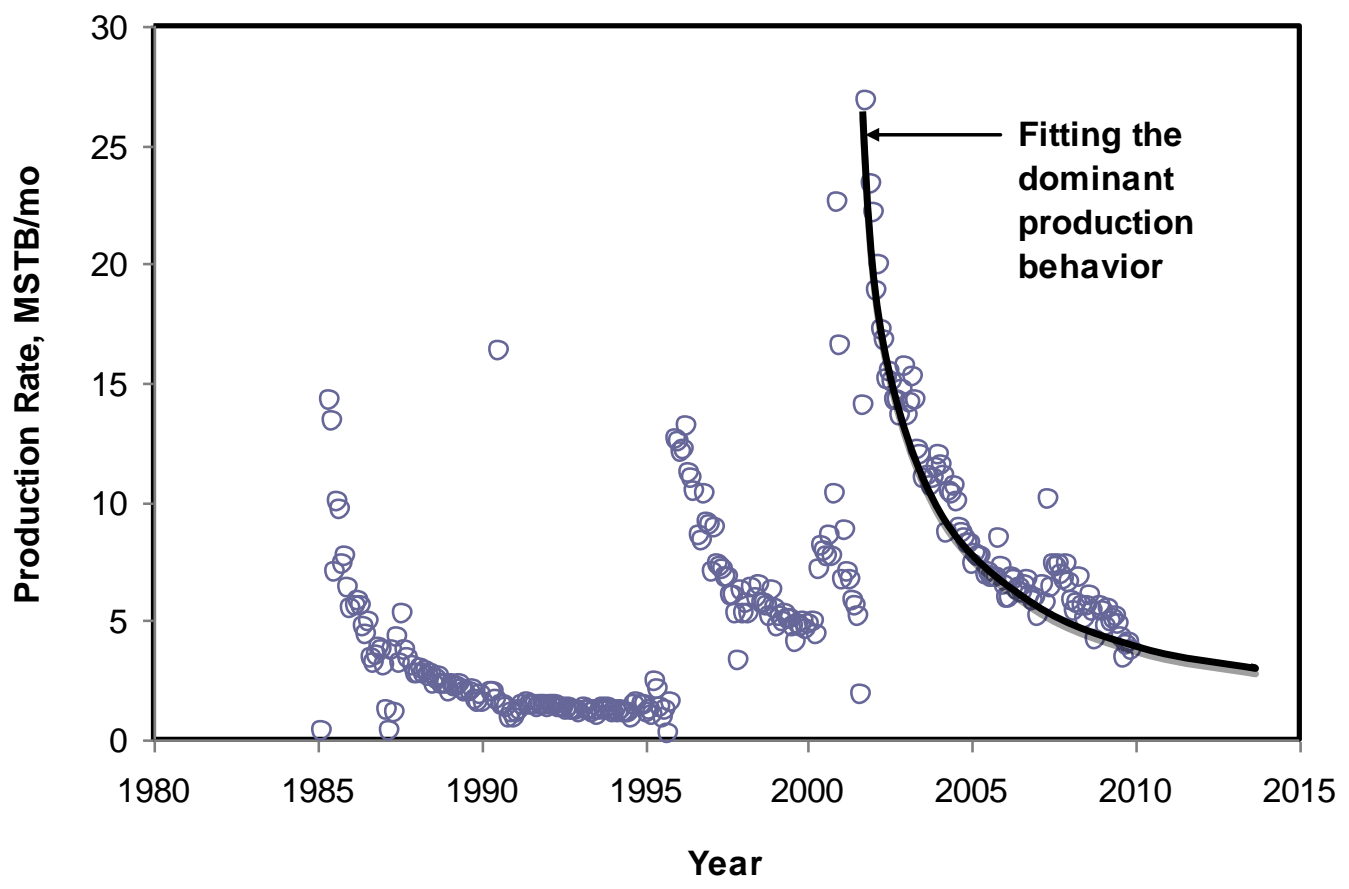

Figure 3.4 - Fitting the dominant production-decline behavior to obtain SEPD parameters.

While investigating wells with production history, we assumed that only one-third of the production history is known and used in the analysis. The remaining half is assumed unknown and used for validation of the predictions. This approach instilled confidence in the solutions obtained. 


\subsection{Determining Model Parameters}

The crucial problem with any curve-fitting analysis procedure is that the selection between the type curve families is ambiguous. Certainly, one may also use nonlinear regression to determine the unknown parameters simultaneously, but the problem of nonuniqueness or ill-conditioning is not easily solved (Valko 2009). Valko suggested a new procedure for SEPD model, in which parameters can be obtained by solving two nonlinear equations. Instead of performing plain nonlinear regression on monthly production data, one-third, two-third, and the last point of cumulative production are calculated. For example, if three years of production history will be used to predict the future performance, cumulative production is calculated at the end of each year. Thereafter, the ratios of two-third to one-third and last point to one-third are calculated in accord with the following equation:

$$
r_{21}=\frac{Q_{\text {second year }}}{Q_{\text {first year }}}, \quad r_{31}=\frac{Q_{\text {third year }}}{Q_{\text {first year }}}
$$

By solving two nonlinear equations, represented by the following expressions, $n$ and $\tau$ parameter pairs are obtained:

$$
\begin{aligned}
& \frac{\Gamma \frac{1}{\mathrm{n}}-\Gamma \frac{1}{\mathrm{n}}, \frac{24}{\tau}^{n}}{\Gamma \frac{1}{\mathrm{n}}-\Gamma \frac{1}{\mathrm{n}^{\prime}},^{\frac{12}{\tau}}}=r_{21} \\
& \frac{\Gamma \frac{1}{\mathrm{n}}-\Gamma \frac{1}{\mathrm{n}}^{\prime}, \frac{36}{\tau}^{n}}{\Gamma \frac{1}{\mathrm{n}}-\Gamma \frac{1}{\mathrm{n}}^{\prime} \frac{12}{\tau}^{n}}=r_{31}
\end{aligned}
$$


This procedure is followed when we calculate the $n$ and $\tau$ parameter pairs in order to obtain parameter distribution which is explained in the next section.

\subsection{Production Data Grouping - A Parameter Distribution Apparatus}

The pragmatic approach is to group existing wells according to the initial rates. The underlying objective of well grouping is to obtain common SEPD model parameters for similar wells in terms of productivity index. Instead of calculating one global set of model parameters, assigning individual parameter sets to groups provides the opportunity to reduce uncertainty of model parameters and also the prediction interval, leading to consistency in forecasting.

Following the evaluation of $n$ and $\tau$ parameter pair, common parameter sets of groups are calculated using the well-known probabilistic criteria of P Index (P10-P50-P90). By constructing the cumulative distribution function or CDF, we obtained high, medium, and low $n$ parameter values for the group. To obtain the $\tau$ parameter for each case (P10P50-P90), we used the following steps:

1. Solve the nonlinear equation for $\tau$ using the high $n$ parameter value or $n_{\mathrm{P} 10}$ as the $n$ parameter. There will be resulting $\tau$ parameters for each well. The median of that series will be $\tau_{\mathrm{P} 10}$. These steps are followed for both the low- and medium- $\tau$ parameters. Fig. 3.5 depicts the procedure used. 


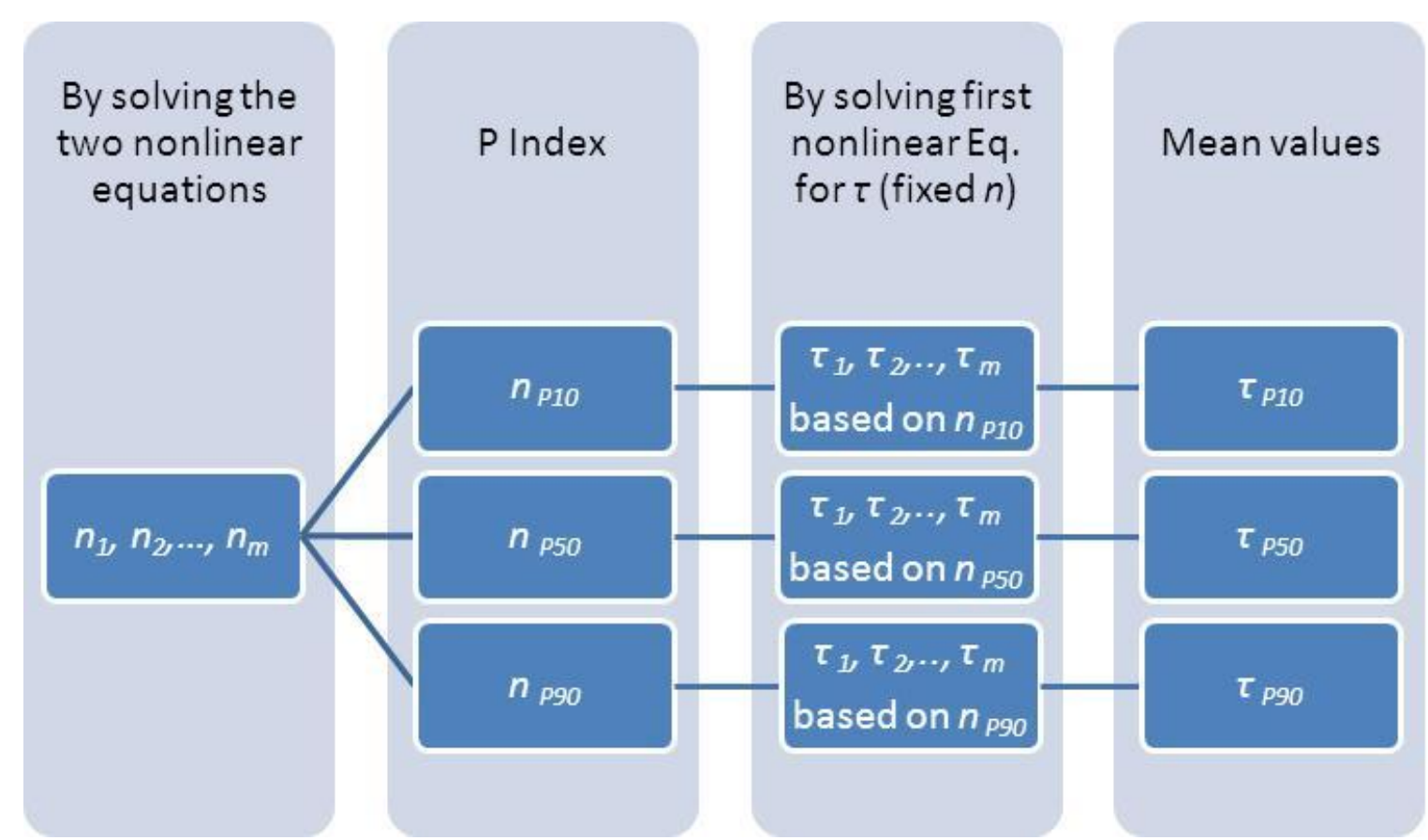

Figure 3.5 - Procedure for obtaining model parameters, $\boldsymbol{n}$ and $\boldsymbol{\tau}$.

2. The third model parameter in SEPD model is $q_{0}$. Several methods may be used for obtaining this parameter in SEPD. For our purposes, we follow the method proposed by Valko and Lee (2010), which obtains $q_{0}$ with incorporating the most recent cumulative production data. As $n$ and $\tau$ parameter pairs are known for groups, $q_{0}$ parameters for individual wells can be obtained using the wells total cumulative production as shown in Eq. 3.12.

$$
q_{0}=\frac{N_{p}}{\frac{\tau}{n} \Gamma \frac{1}{n}-\Gamma \frac{1}{n}, \frac{t}{\tau}^{n}}
$$

At this stage, we generate individual wells' forecast as the $n$ and $\tau$ parameters of the group and also the $q_{0}$ parameter of the wells are all available. Fig. 3.6 shows cumulative production of a well in the Barnett field and its probabilistic forecast. Spread of the 
prediction is a result of P10 and P90 values of $n$ and $\tau$ model parameters. When the well count in a group is large, a wider spread is expected. The exterior lines show a forecast with a group of 500 wells and interior lines are results of a group of 100 wells. Whenever appropriate, the use of a small group of wells reduces the uncertainty.

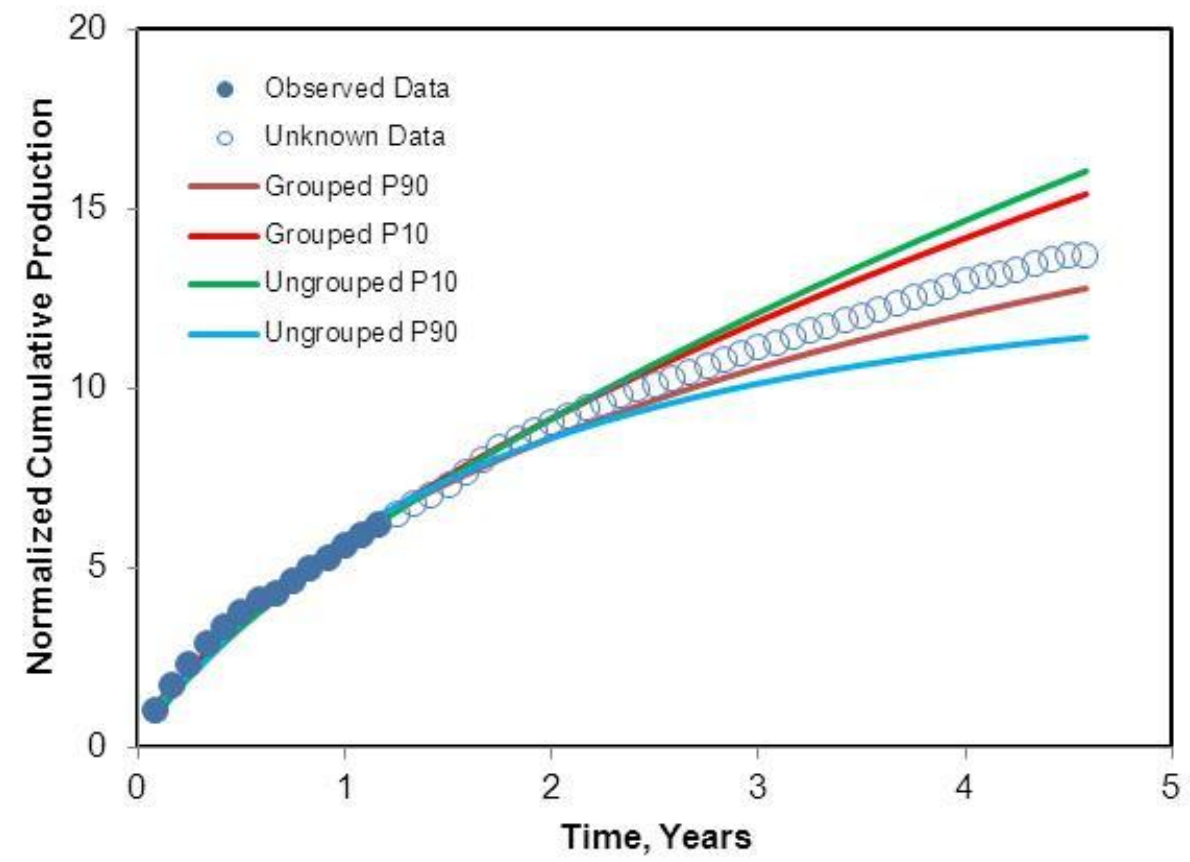

Figure 3.6 - Fitting the dominant production-decline behavior to obtain SEPD parameters. 


\section{CHAPTER IV}

\section{APPLICATION OF THE METHOD TO SYNTHETIC AND FIELD EXAMPLES}

\subsection{Synthetic Case Demonstration Examples}

In this section we provide the validation of the methodology by analyzing synthetic oil and gas cases simulated as mentioned in previous chapter. We simulate a group of 27 gas wells using Marcellus Shale reservoir and well properties, and a group of 27 oil wells using Elm Coulee oil wells of Bakken reservoir and well properties. In regard of grouping, pragmatic approach would be grouping wells based on their similar productivity indices, however since there are few simulated production data, we treat all 27 wells as a single group for both cases. Our goal is to design a forecast using common $n$ and $\tau$ parameters for all generated production data in each case. During analysis we presumed that only seven years of history is known, and the remaining production is forecasted and compared to the simulated data.

\subsubsection{Synthetic Example 1: Elm Coulee Oil Field}

Our first example is synthetic oil field case where we attempt to design 40 years of production history of 27 wells. Fig. 4.1 presents the results for one of the wells. Note that the suggested approach tends to produce a narrow confidence interval for long-time forecasting, bracketing the actual recovery. Fig. 4.1 shows that the incremental production between P10 and P50 is larger than the one between P90 and P50, which is a direct consequence of distribution of reservoir parameters. 

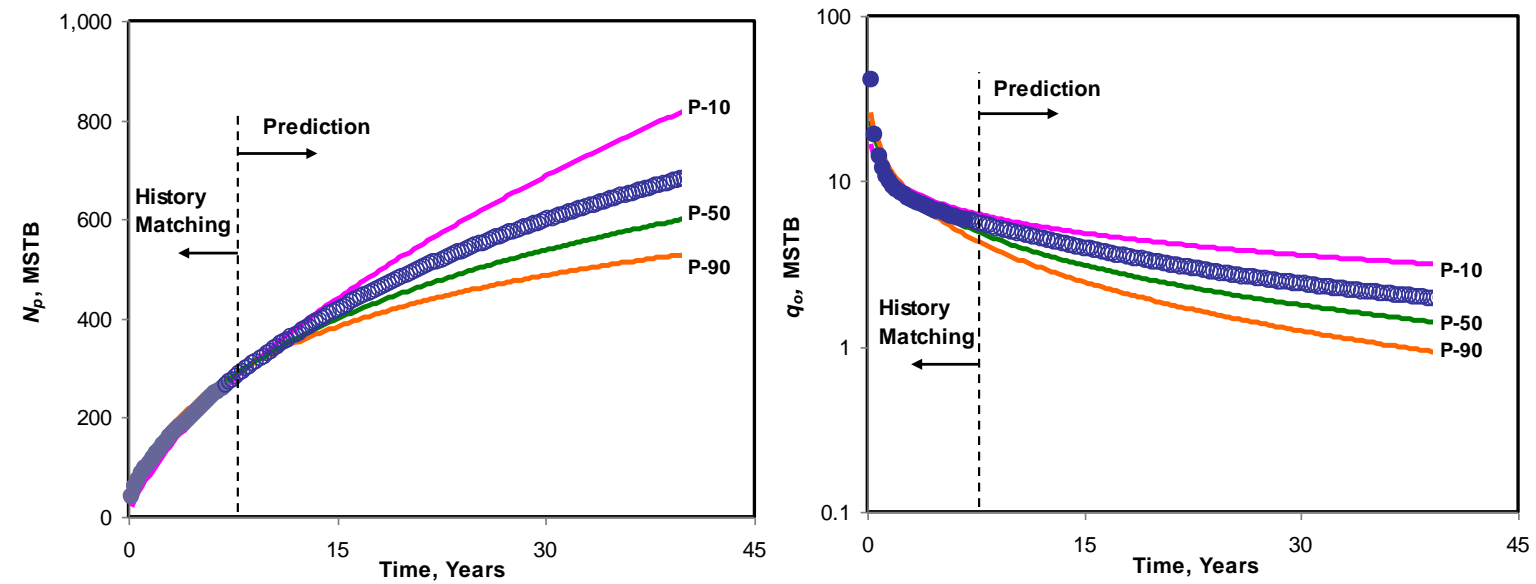

Figure 4.1 - Synthetic oil case - Production forecast up to 40 years of one of the wells.

Table 4.1 shows the $n$ and $\tau$ parameter distribution for this example. Although we treat all wells as a single group, there is no significant difference between P10-P90 trends which yields a narrower confidence interval.

Table 4.1 Common $n$ and $\tau$ parameters for synthetic Elm Coulee oil field.

\begin{tabular}{|l|l|l|c|c|}
\hline$n_{P 10}$ & 0.164 & & $\tau_{P 10}$ & 0.055 \\
\cline { 1 - 1 }$n_{P 50}$ & 0.215 & & $\tau_{P 50}$ & 0.206 \\
\cline { 1 - 1 }$n_{P 90}$ & \multirow{2}{*}{0.236} & & $\tau_{P 90}$ & 0.273 \\
\hline
\end{tabular}

The overall statistics of the analysis results for the set of 27 synthetic production histories for oil case is shown in Fig. 4.2. Green bars represent the P10-P90 interval and red arrows are the actual recovery for 40 years. The model is able to capture the actual 
recovery within the P10-P90 interval for this example, except for the 23rd simulation run. Note that oil example yields to pessimistic results.

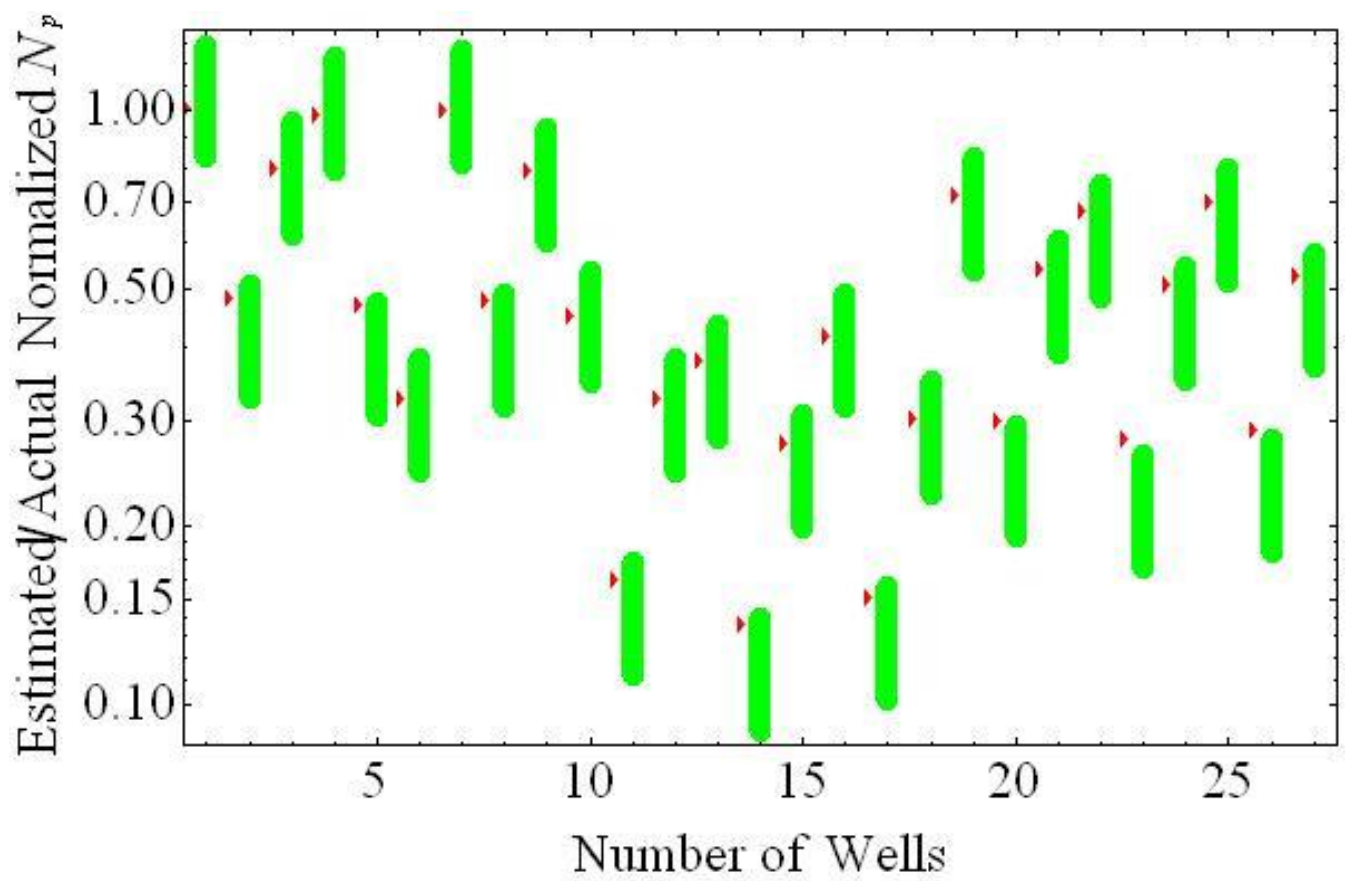

Figure 4.2 - Estimates and actual recovery of 27 wells after 40 years of history in synthetic oil field.

\subsubsection{Synthetic Example 2: Marcellus Gas Field}

Another synthetic example is a Marcellus gas field case where we generate 30 years of production history of 27 wells. Table 4.2 shows the $n$ and $\tau$ parameter distribution for this example. Results suggest a narrower parameter range than oil case. Also in this example, the parameter difference between P10 and P50 is smaller than the one between P90 and P50, in contrary to oil example. 
Table 4.2 Common $\boldsymbol{n}$ and $\boldsymbol{\tau}$ parameters for synthetic Marcellus gas field.

\begin{tabular}{|c|c|c|c|c|}
\hline$n_{P 10}$ & 0.19 & & $\tau_{P 10}$ & 0.246 \\
\cline { 1 - 1 }$n_{P 50}$ & 0.203 & & $\tau_{P 50}$ & 0.361 \\
\hline$n_{P 90}$ & 0.236 & & $\tau_{P 90}$ & 0.397 \\
\hline
\end{tabular}

The overall statistics of the analysis results for the set of 27 synthetic production histories for gas case is shown in Fig. 4.3. Green bars represent the P10-P90 interval and red arrows are the actual recovery for 30 years. Although gas case analysis results suggests a narrower confidence interval than oil case, methodology is able to bracket the actual recovery within the interval in all cases.

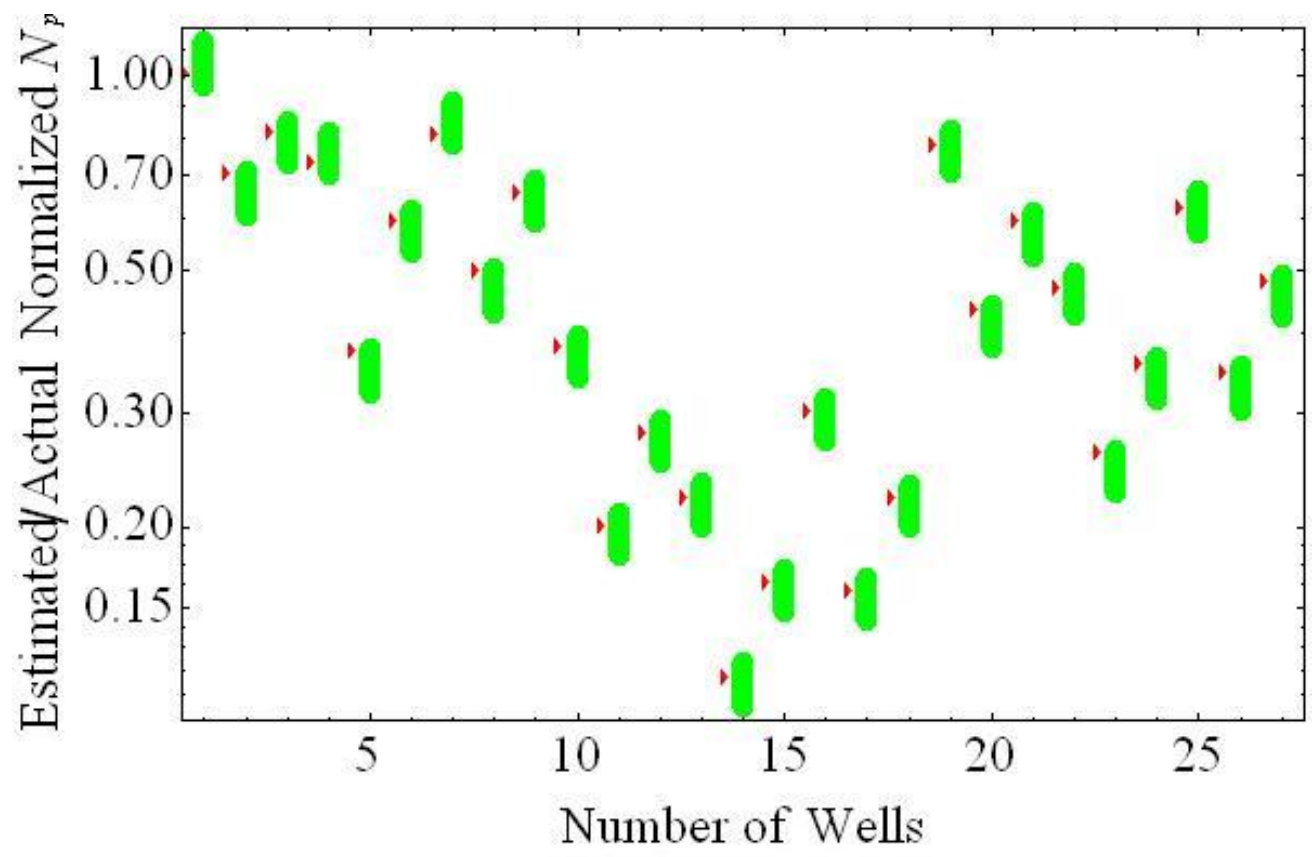

Figure 4.3 - Estimates and actual recovery of 27 wells after 30 years of history in synthetic gas field. 


\subsection{Field Case Demonstration Examples}

In this section we demonstrate three field examples where monthly production data of wells were taken from publicly open HPDI database. These fields include Barnett Shale in Texas (500 wells), and Marcellus Shale in Pennsylvania and West Virginia (224 wells) involving gas production and Montana's Elm Coulee field producing from the Bakken oil shale (400 wells). This section aims to present the utility of proposed methodology for assessing reserves in tight gas and oil reservoirs. The overall results are presented in Table 4.3 at the end of this section.

\subsubsection{Field Example 1: Barnett Gas Field}

The first field example is a group of 500 wells in Barnett Shale gas reservoir in Texas. Selected wells started production within in the year 2004 and have been on surveillance (monthly measurement of gas production) up to the present day. Underlying motive of selecting 2004 wells is because our interest in novel wells in Barnett Shale. As Valko and Lee (2010) pointed out, the novel horizontal wells in the Barnett Shale, which were completed with multiple intersecting fractures, gained acceptance in 2004 and has become almost exclusive since then. Another reason of using young wells is to avoid the production interruptions (e.g., restimulation, shut-in periods, etc.). As 500 wells are examined in this field, we expect to see a scattered distribution of maximum monthly productions. In Fig. 4.4 we observe that inspected wells can be assembled in four groups. 


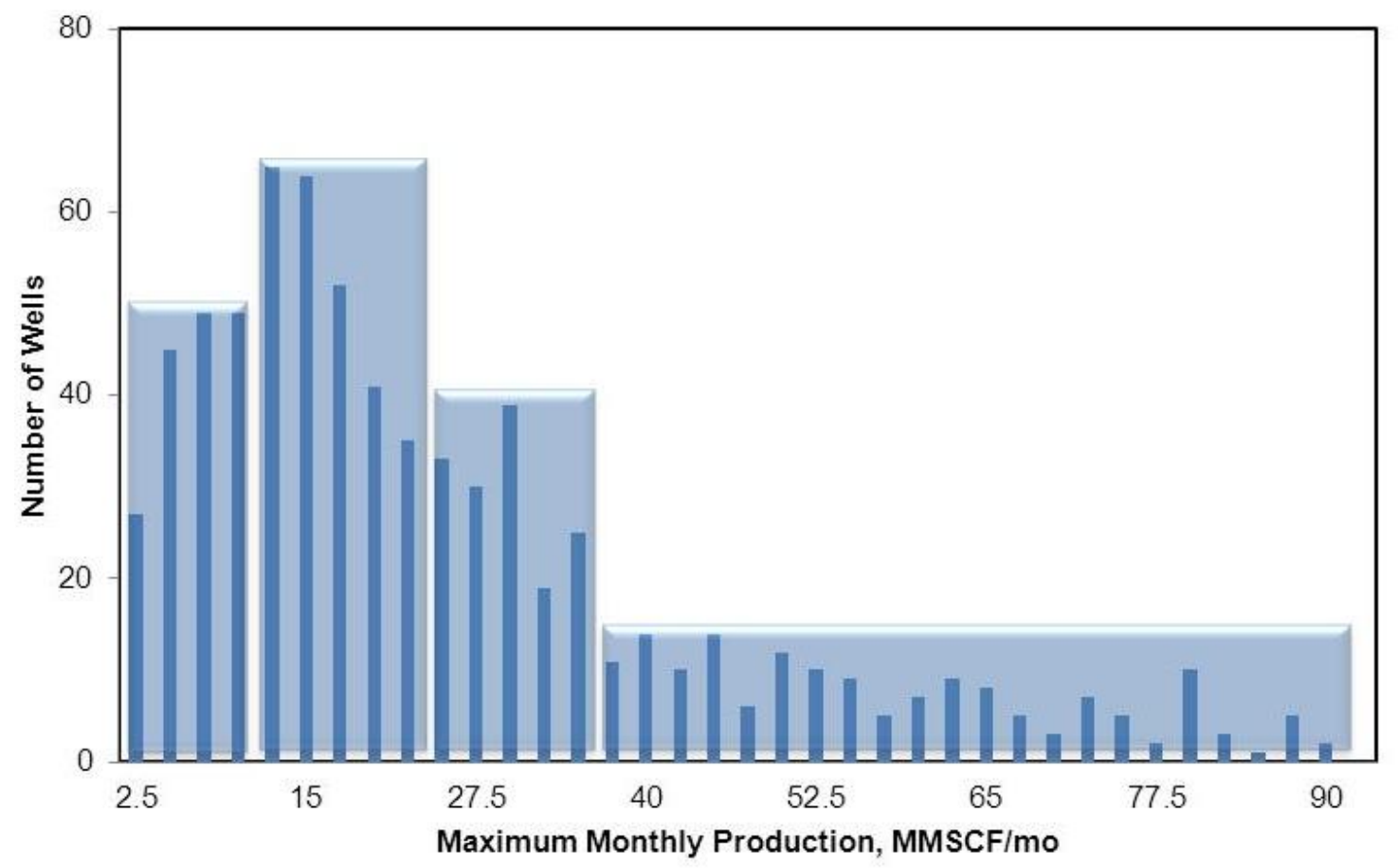

Figure 4.4 - Grouping of Barnett Shale wells based on their peak production.

Fig. 4.5 demonstrates the distribution of $n$ and $\tau$ parameters for four groups. It is difficult to make a generalization on behaviors of the parameter pairs from this figure as $\tau$ parameter distribution behaves chaotic, however $n_{P 90}$ and $n_{P 50}$ values are quite stable whereas $n_{P 10}$ values tend to increase exponentially. It is tempting to say from this figure that $n$ exponent can be considered as a common parameter for all wells while $\tau$ parameters dictate different P10-P90 intervals for different groups. 

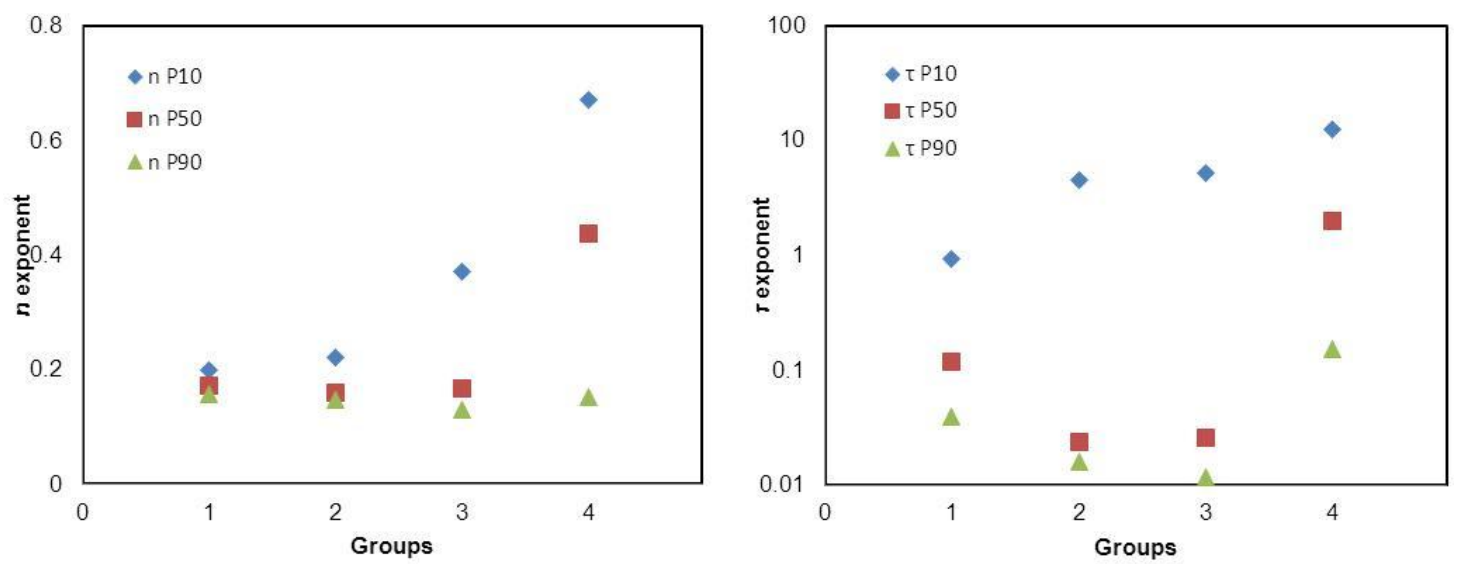

Figure 4.5 - Distribution of $\boldsymbol{n}$ and $\boldsymbol{\tau}$ parameter pairs of Barnett Shale gas field example.

In Fig. 4.6 we present the monthly production data of a gas well in Barnett Shale. We note that production data follows a smooth trend which should yield a stable forecast.

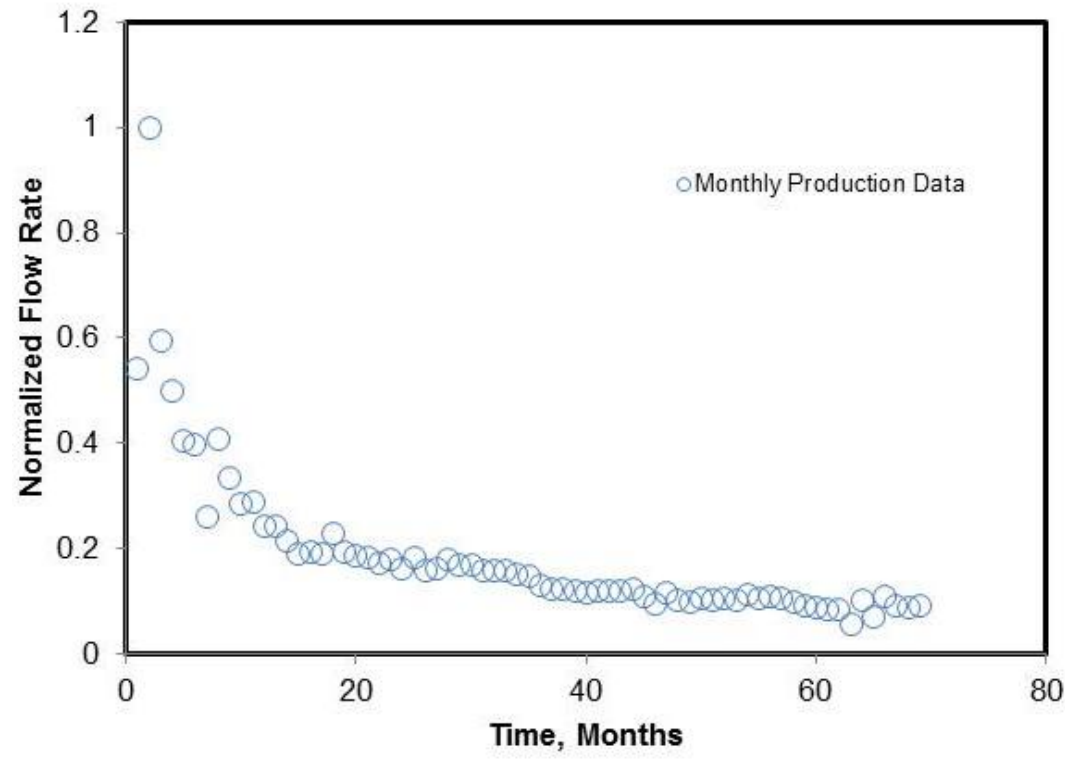

Figure 4.6 - Monthly production history plot for first field example of Barnett Shale. 
Fig. 4.7 shows the actual decline behavior and its probabilistic forecast up to five years for one of the wells in Barnett Shale. This well is a member of the second group based on its maximum monthly production. The computed P50 trend clearly exhibits the actual production decline also P10-P90 interval covers the actual behavior with a thin gap within.

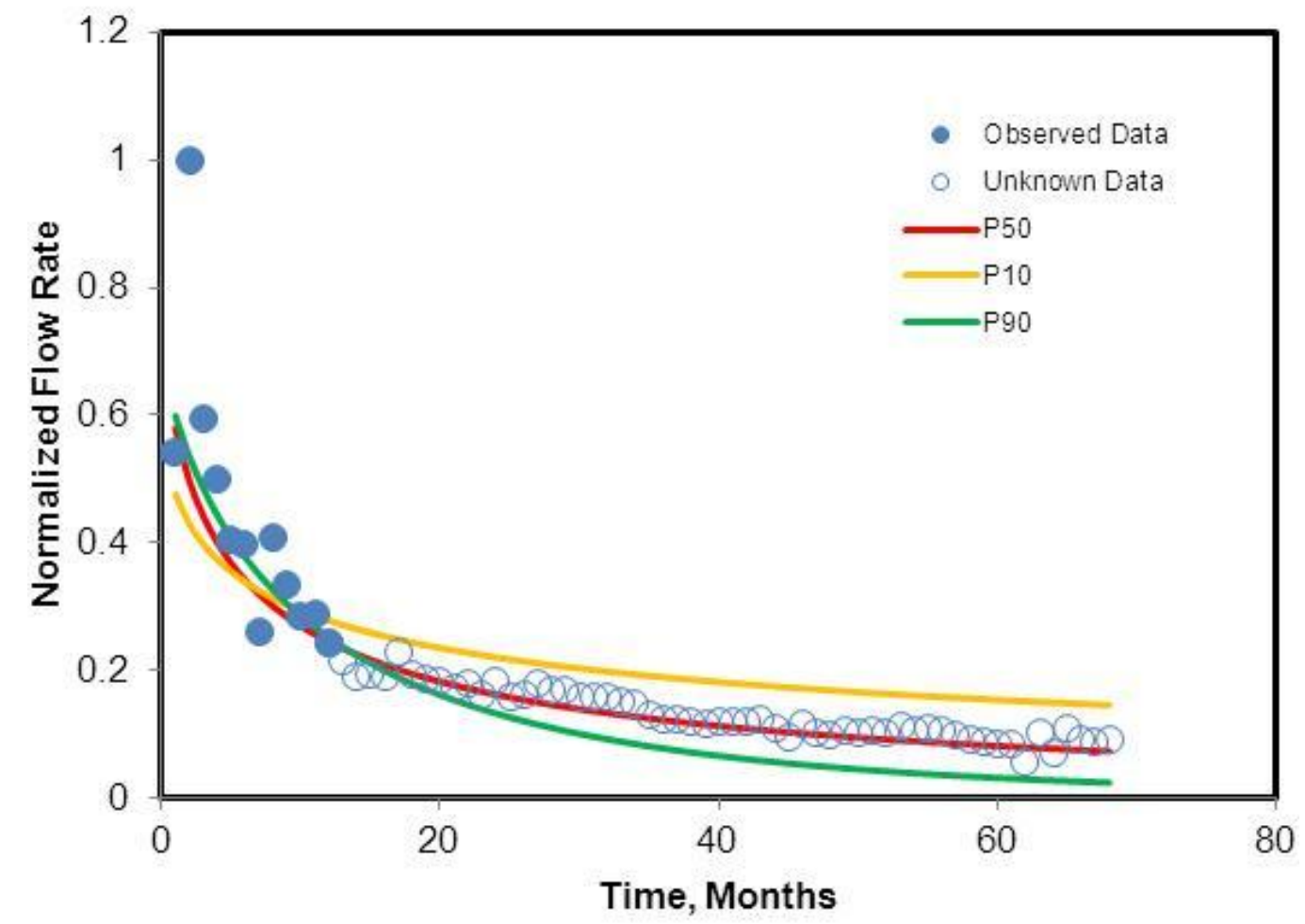

Figure 4.7 - Actual and estimated production decline of first field example in Barnett Shale.

Fig. 4.8 demonstrates the recovery potential plot of this well. As mentioned earlier recovery potential plot gives an understanding of estimated recoverable reserves. Fig. 4.8 suggests that this gas well already delivered the half of its capacity. 


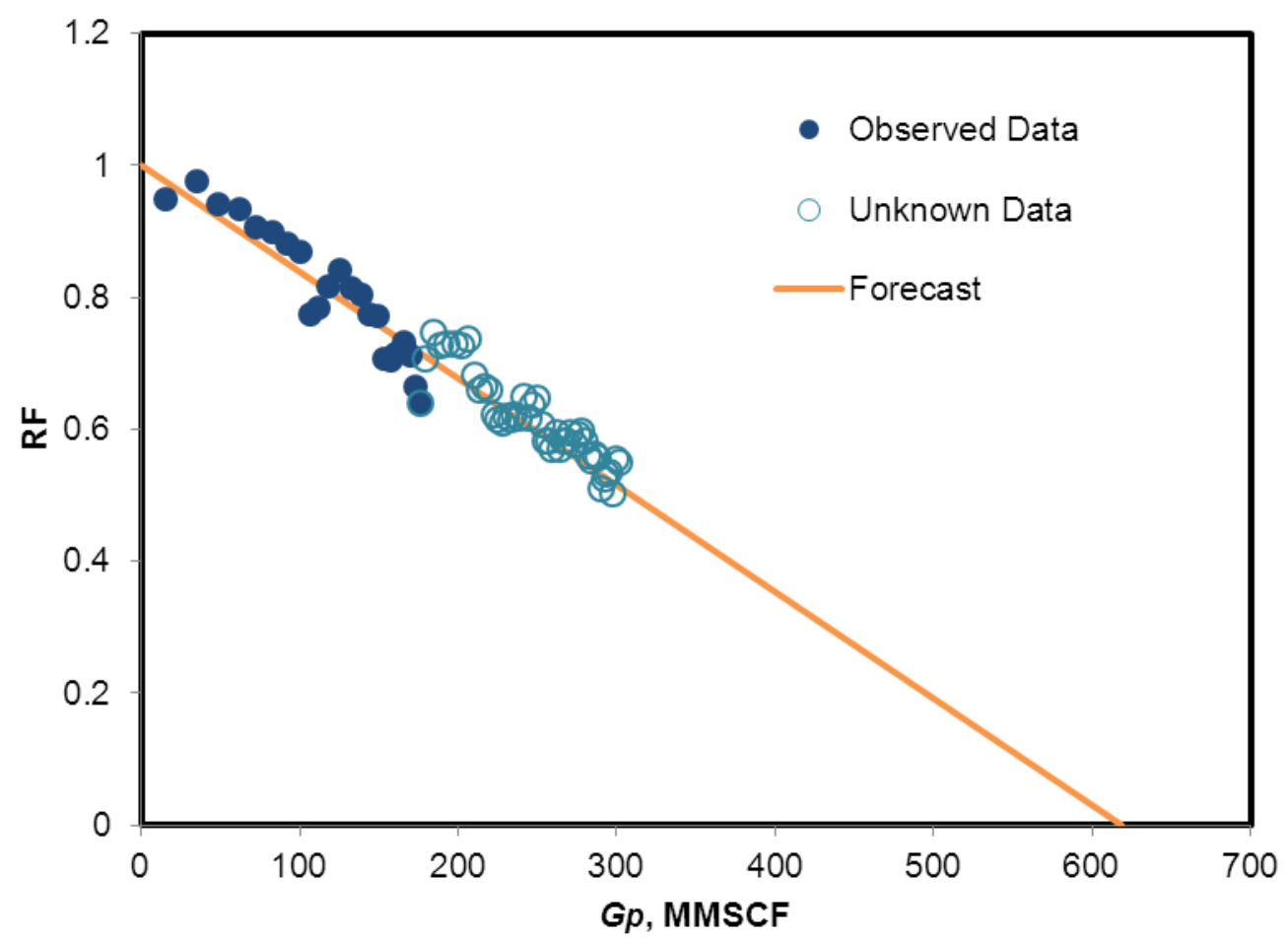

Figure 4.8 - Recovery potential plot of first field example in Barnett Shale.

Fig. 4.9 shows data from a well that started production in 1999 and continues to produce to this day. When the model parameters were estimated for the Barnett well group, we did not include this specific well because we wanted to see if the groups that we generated for Barnett could represent the entire field. 


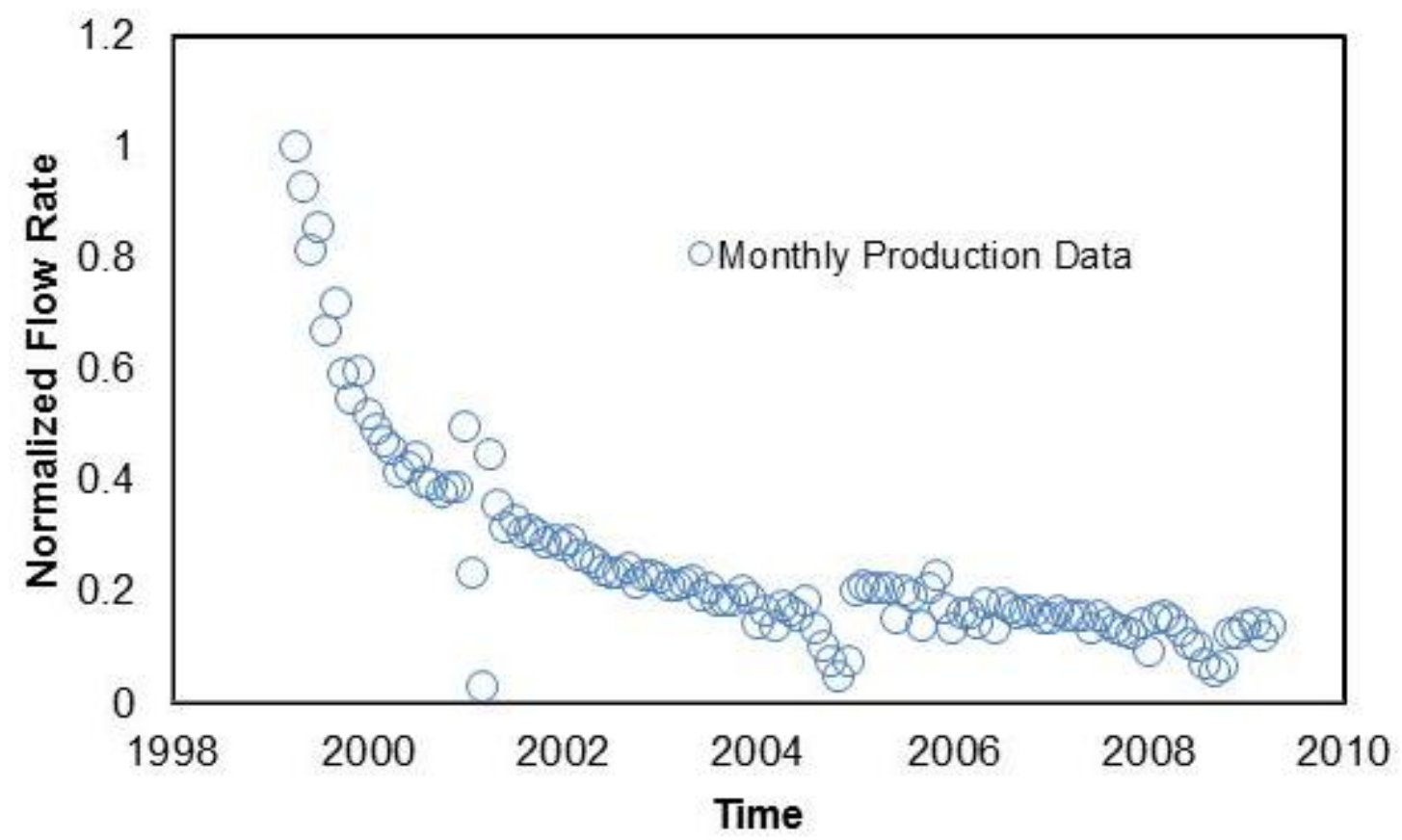

Figure 4.9 - Monthly production history plot for second field example of Barnett Shale.

After generating four groups for the Barnett field, we observe that this specific well falls into the second group based on its peak production. Using the second group's $n$ and $\tau$ parameter pair for this well gives the production forecast presented in Fig. 4.10. 


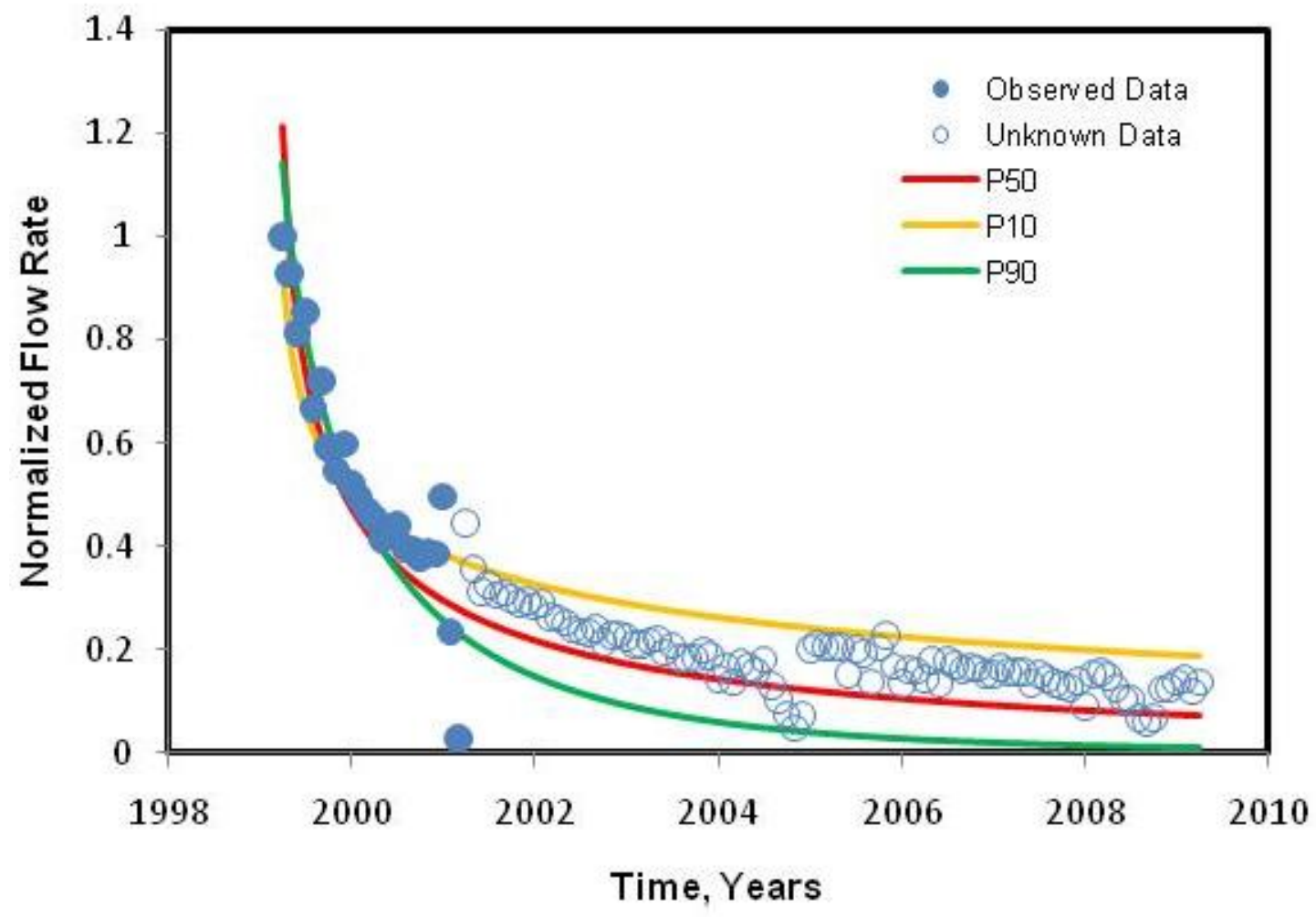

Figure 4.10 - Production forecast of the second field example in Barnett Shale.

After groups are determined using a sufficient number of wells, other wells' future performance can be predicted by monitoring the new well's peak production and placing it into the appropriate group. This attribute of the methodology is very useful when dealing with wells whose parameters are difficult to obtain because of deviations in trend owing to restimulation, artificial-lift installation, etc..

Fig. 4.11 illustrates randomly selected wells forecast in the Barnett Shale gas play. Red arrows are the actual recovery up to the last available date and green bars are the P10/P90 index generated using half of the production history for each well. 


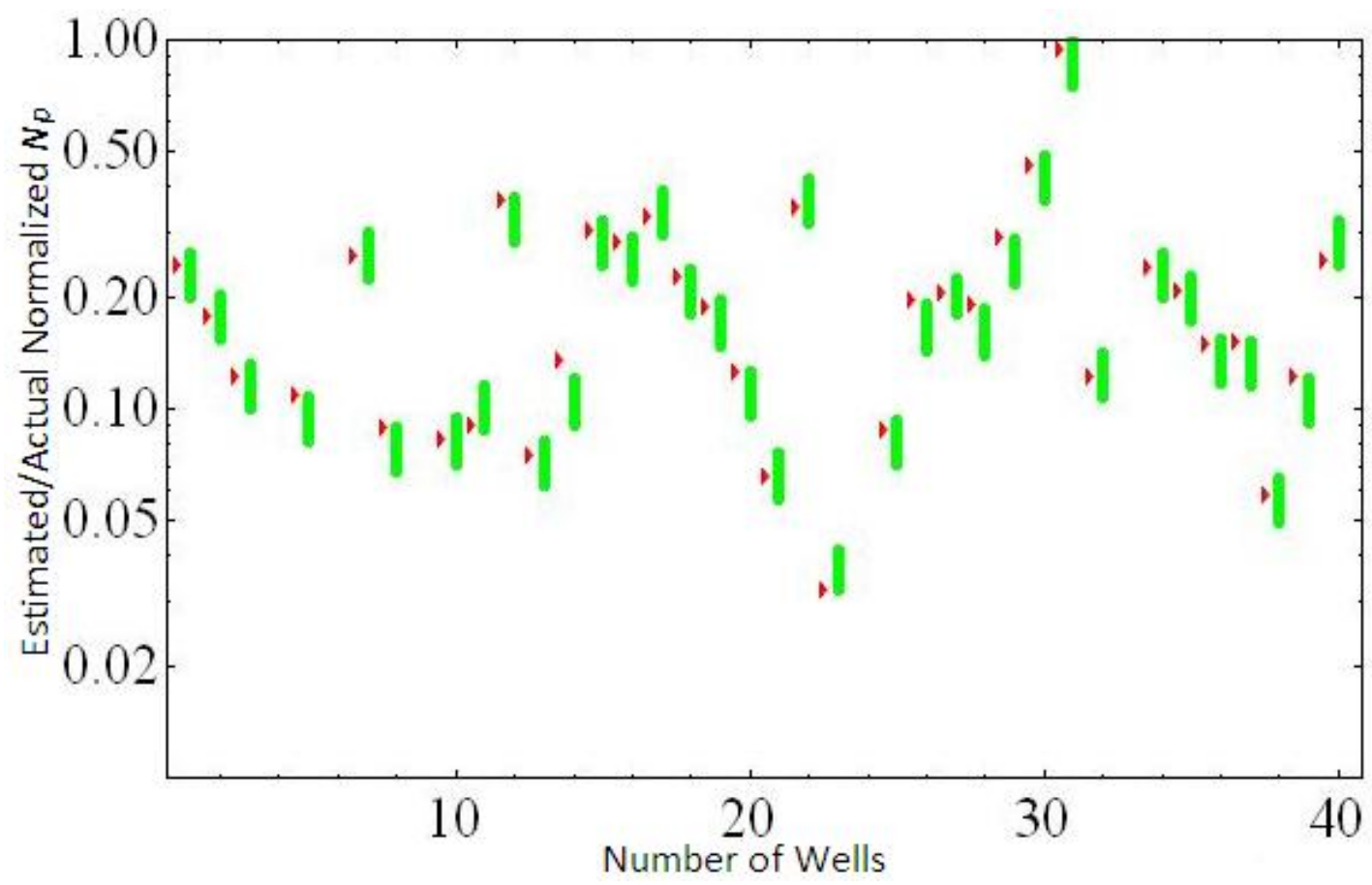

Figure 4.11 - Estimates and actual recovery of 40 wells in Barnett Shale gas play.

The coverage of the actual data by obtained P10-P90 intervals of all wells seem consistent. It was expected to obtain an accurate and consistent forecast interval for this group of wells considering the good quality of the data and relatively short lengths of production in Barnett Shale wells.

\subsubsection{Field Example 2: Marcellus Gas Field}

Although Marcellus Shale is considered as a shale gas play which is currently in the early stages of development, it has the potential to be one of the largest natural gas plays in the United States (Arthur, Bohm, and Coughlin 2008). Marcellus Shale play is a highly organic black shale which extends New York, Pennsylvania, Ohio, and West Virginia. Eastern side of the basin also covers minor portions of Maryland and Virginia. 
As mentioned earlier we randomly select 224 wells which started producing in 2004 as our purpose is to examine the wells in which new hydraulic fracture technology is used. Fig. 4.12 demonstrates the three groups of wells based on their maximum monthly production. Since the number of wells are relatively small and there is no extensive sparse in the data, dividing the wells into three group seems appropriate.

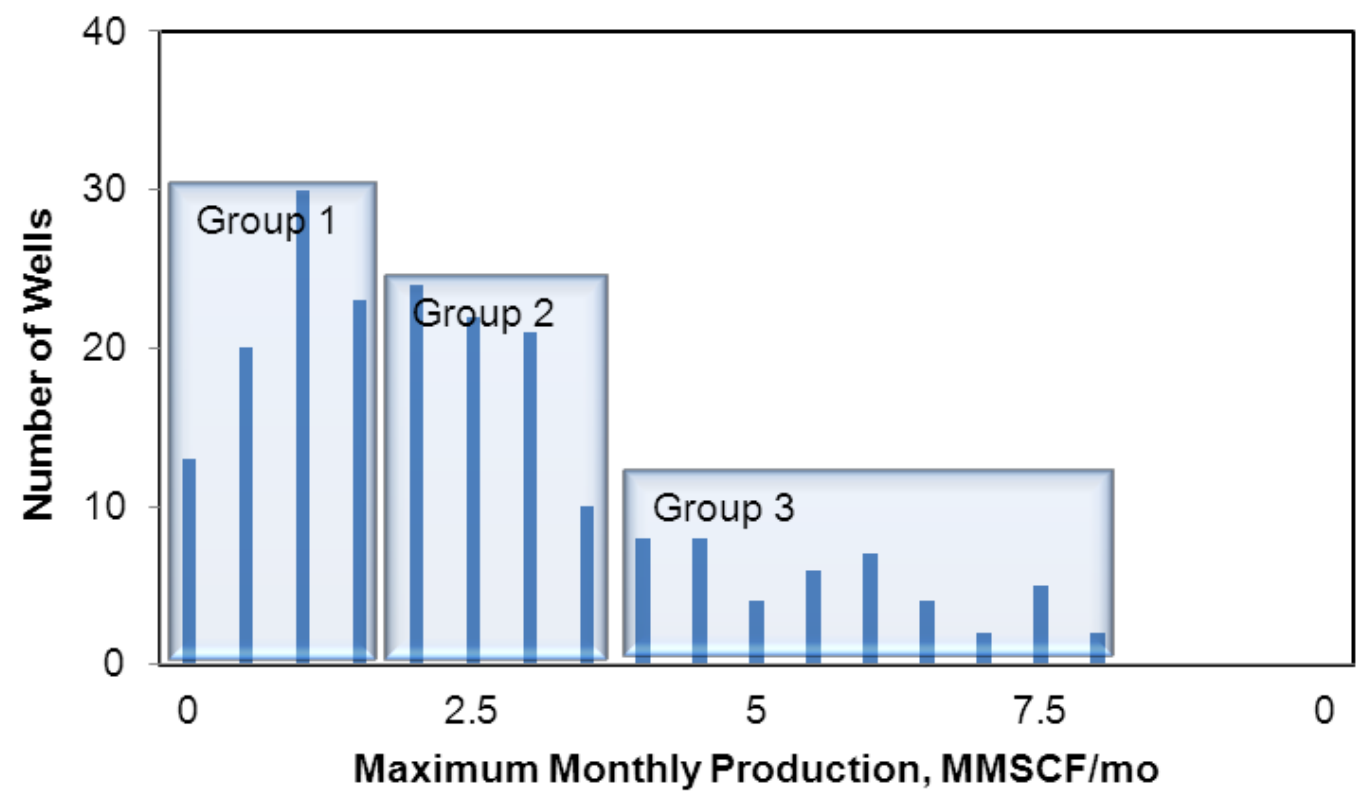

Figure 4.12 - Grouping of Marcellus Shale wells based on their peak production.

Fig. 4.13 illustrates the distribution of $n$ and $\tau$ parameters. Similar to Barnett Shale example nP90 values of the groups are very similar. Distribution of other trends remains chaotic. 

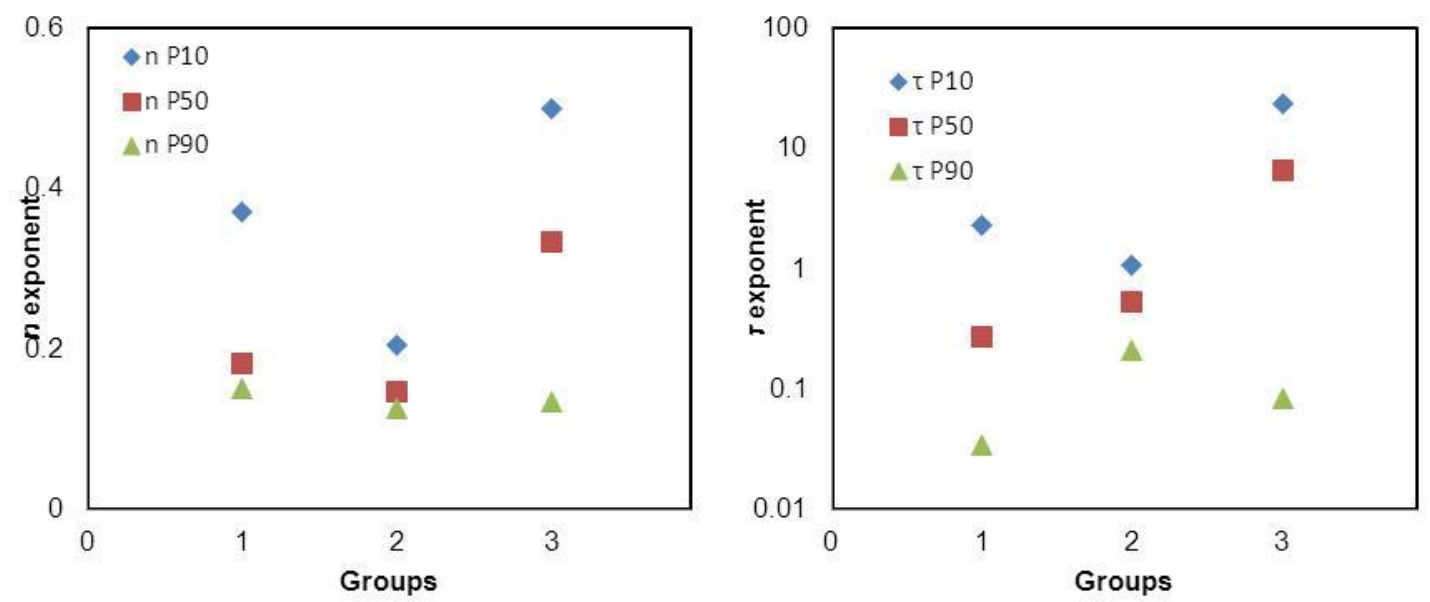

Figure 4.13 - Distribution of $\boldsymbol{n}$ and $\boldsymbol{\tau}$ parameter pairs of Marcellus Shale gas field.

After calculating the parameter distributions of each group, we go into individual wells in order to examine the success of the proposed methodology. We select a well which has a production data more than five years in Fig. 4.14.

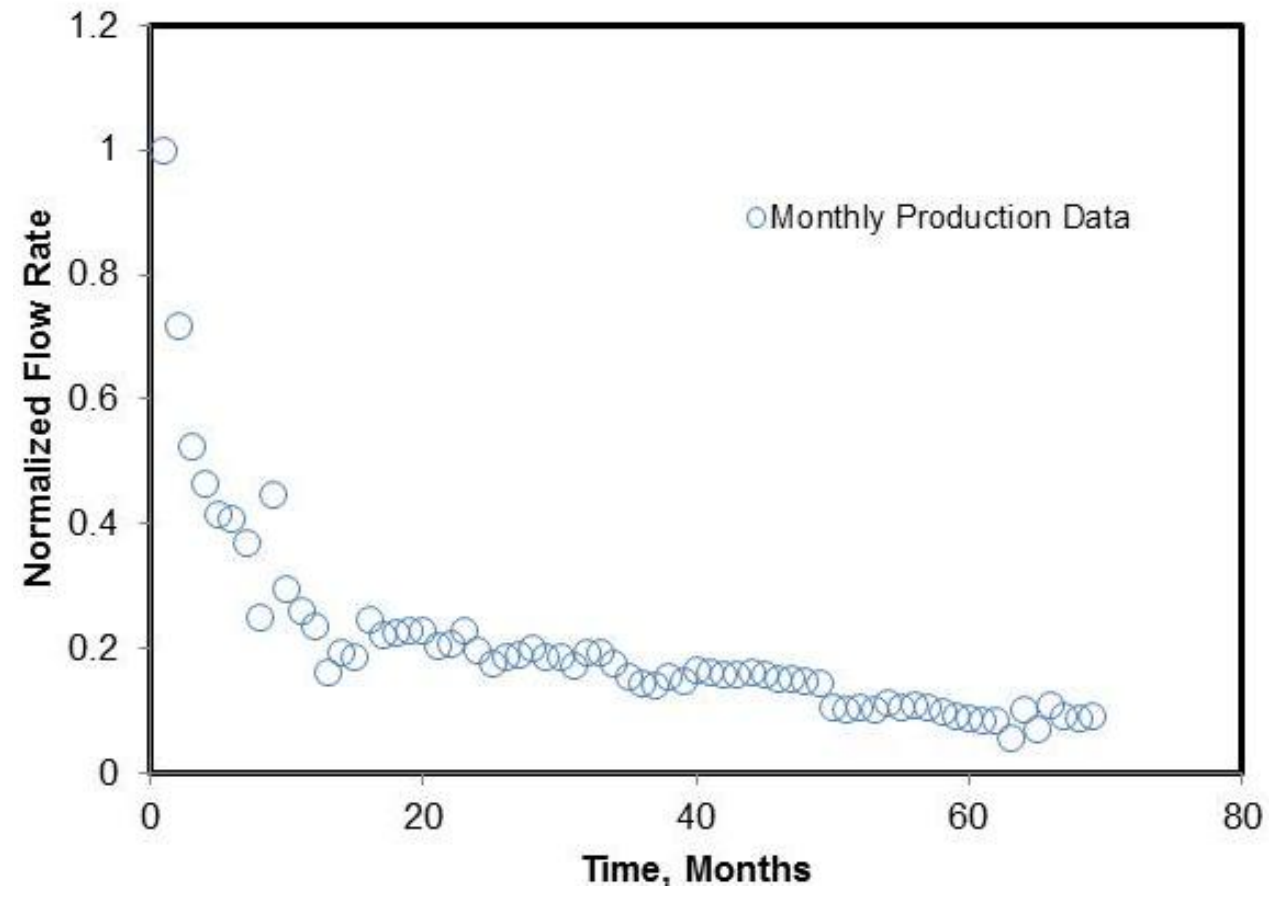

Figure 4.14 - Monthly production history plot for first field example of Marcellus

Shale. 
As seen in Fig. 4.15, analysis of the well shows that method successfully represents the decline behavior and presents a reasonable P10-P90 interval.

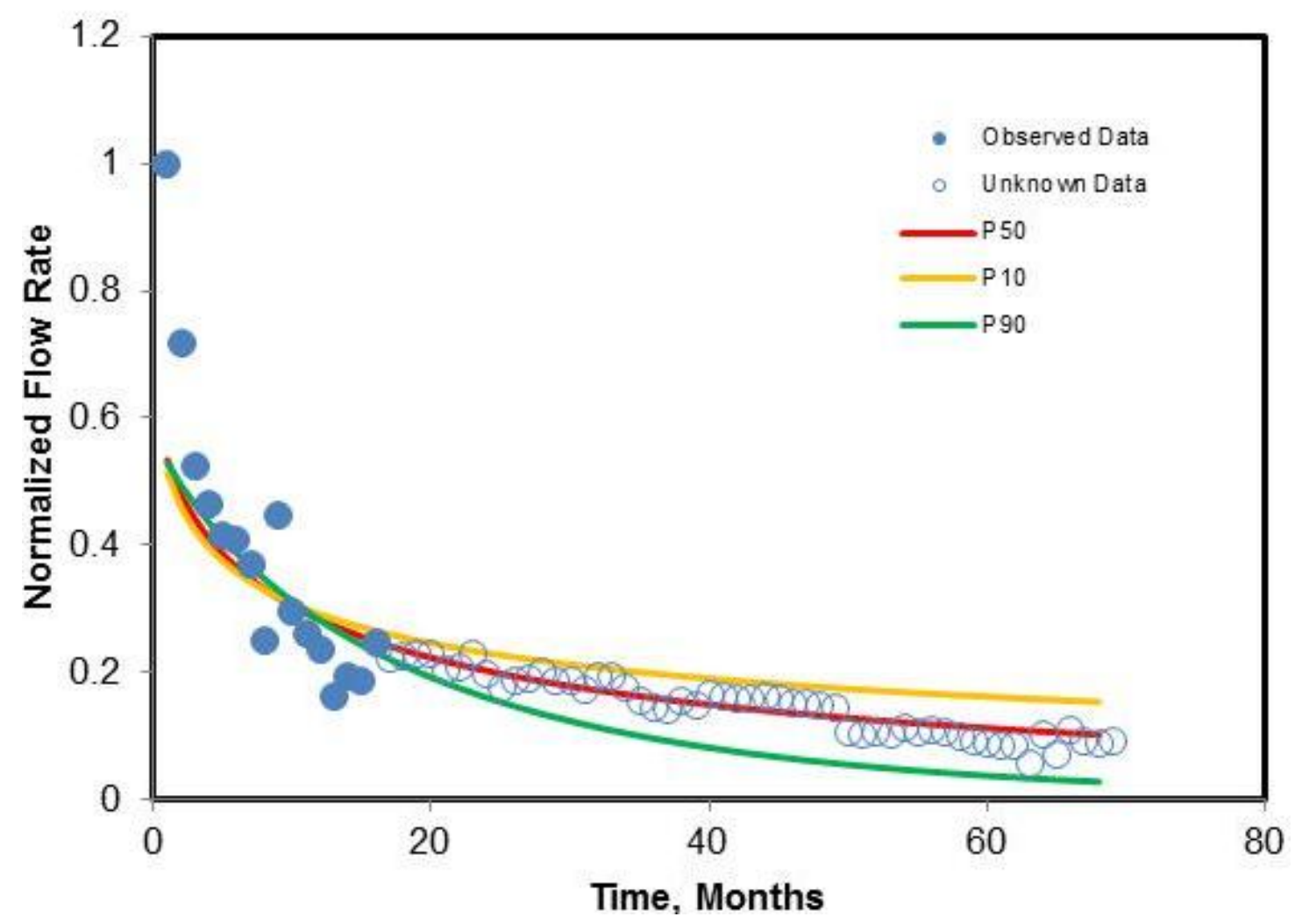

Figure 4.15 - Production forecast of the first field example in Marcellus Shale.

We apply the recovery potential analysis to the same well using P50 parameters as we see that the decline trend follows the P50 line. Analysis shows that the well has 46.2 MMscf total recoverable gas and delivered 67\% percent of its potential as seen in Fig. 4.16. 


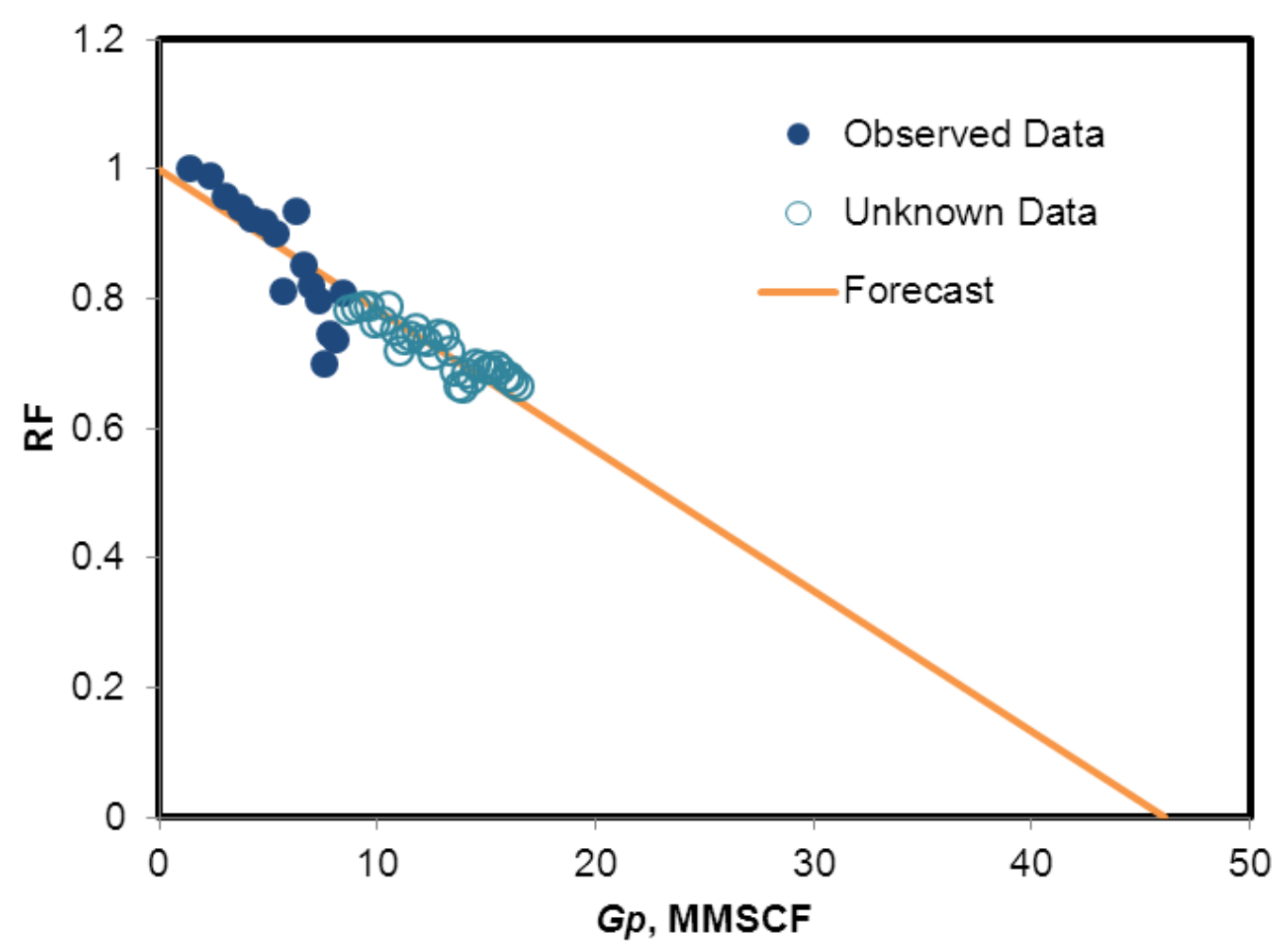

Figure 4.16 - Recovery potential plot of the second field example in Marcellus

Shale.

We examine a second well in Marcellus Shale. This well has a production data spans less than five years as seen in Fig. 4.17. Visual examination of the Fig. 4.17 yields to a smooth decline. 


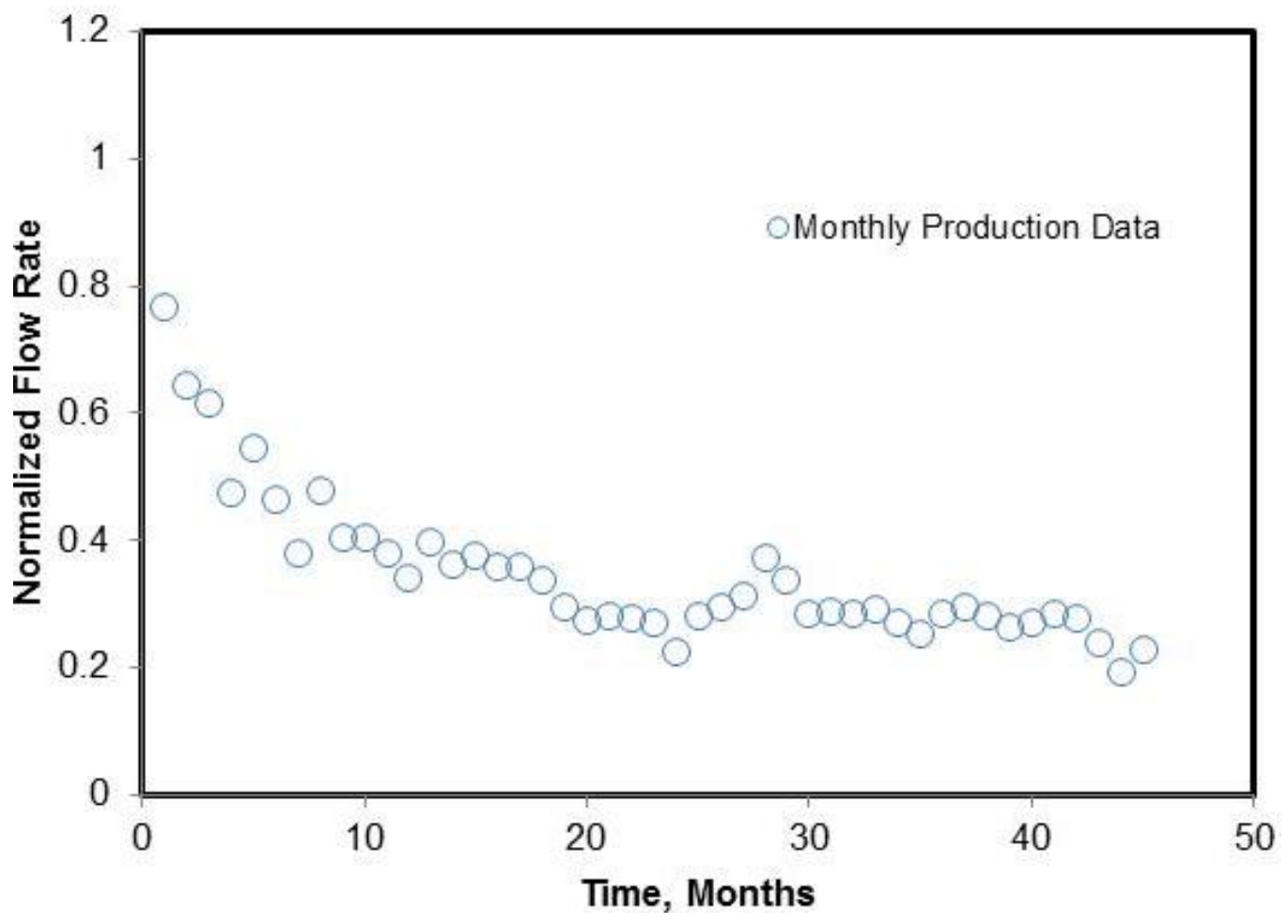

Figure 4.17 - Monthly production history plot for second field example of Marcellus Shale.

Applying our analysis shows that decline of the production data follows P50 trend until 25 months and then changes to P10 trend. Although method captures the decline behavior within the P10-P90 interval, it is not immediately obvious from the Fig. 4.18 that why the decline behavior changes from P50 to P10 trend. 


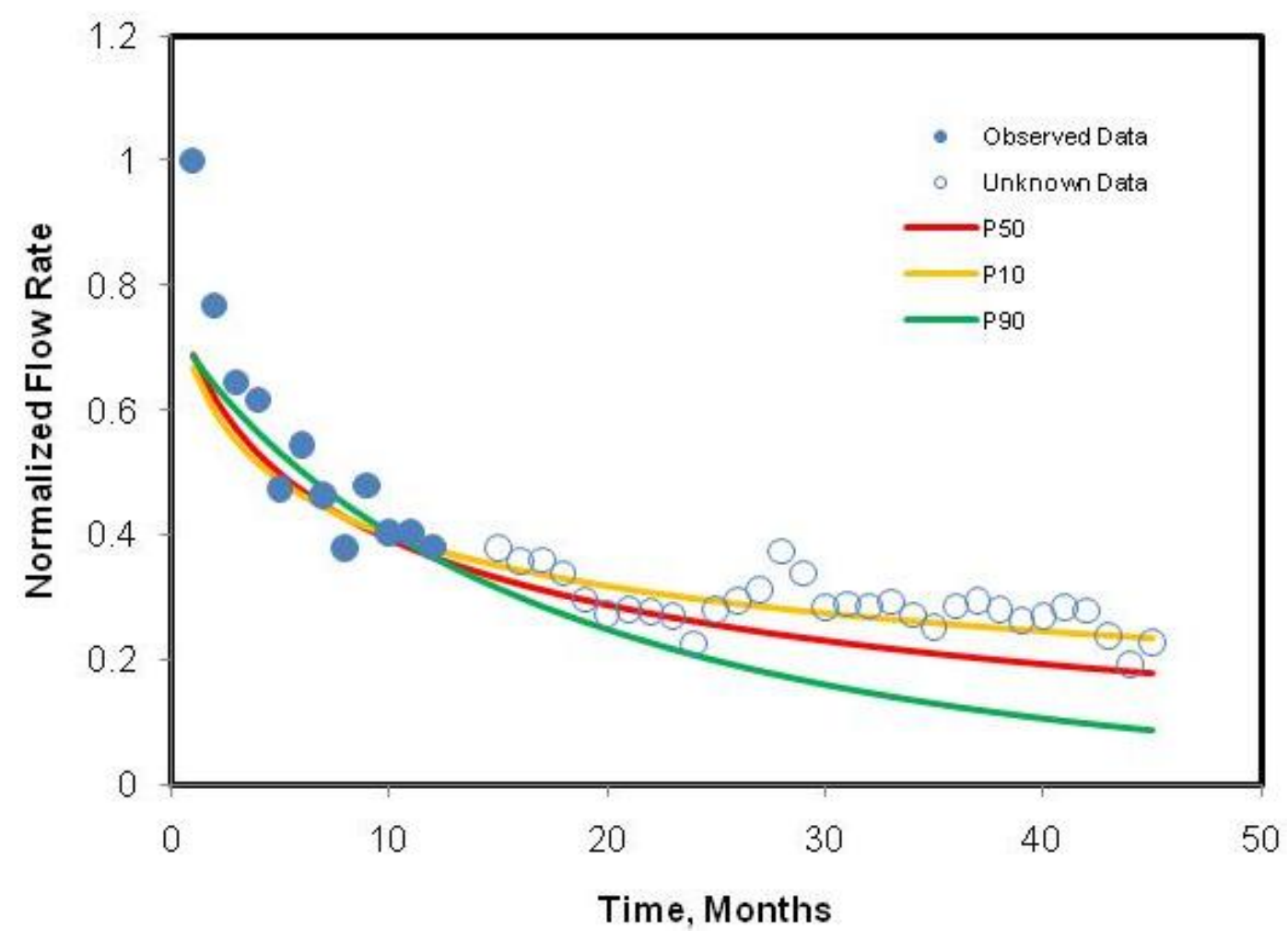

Figure 4.18 - Production forecast of the second field example in Marcellus Shale.

We construct the recovery potential analysis plot in order to further analysis the reason of the change in decline. Fig. 4.19 shows very clearly that there was an interference to the well after 25 months. This operation did not change the behavior of the decline but it can be said that it added additional reserves to the well. Extrapolating the new decline behavior gives the same straight-line but shifted to the right. This event results in an EUR 80.1 MMscf which is close enough to P10 estimate of 79.8 MMscf. 


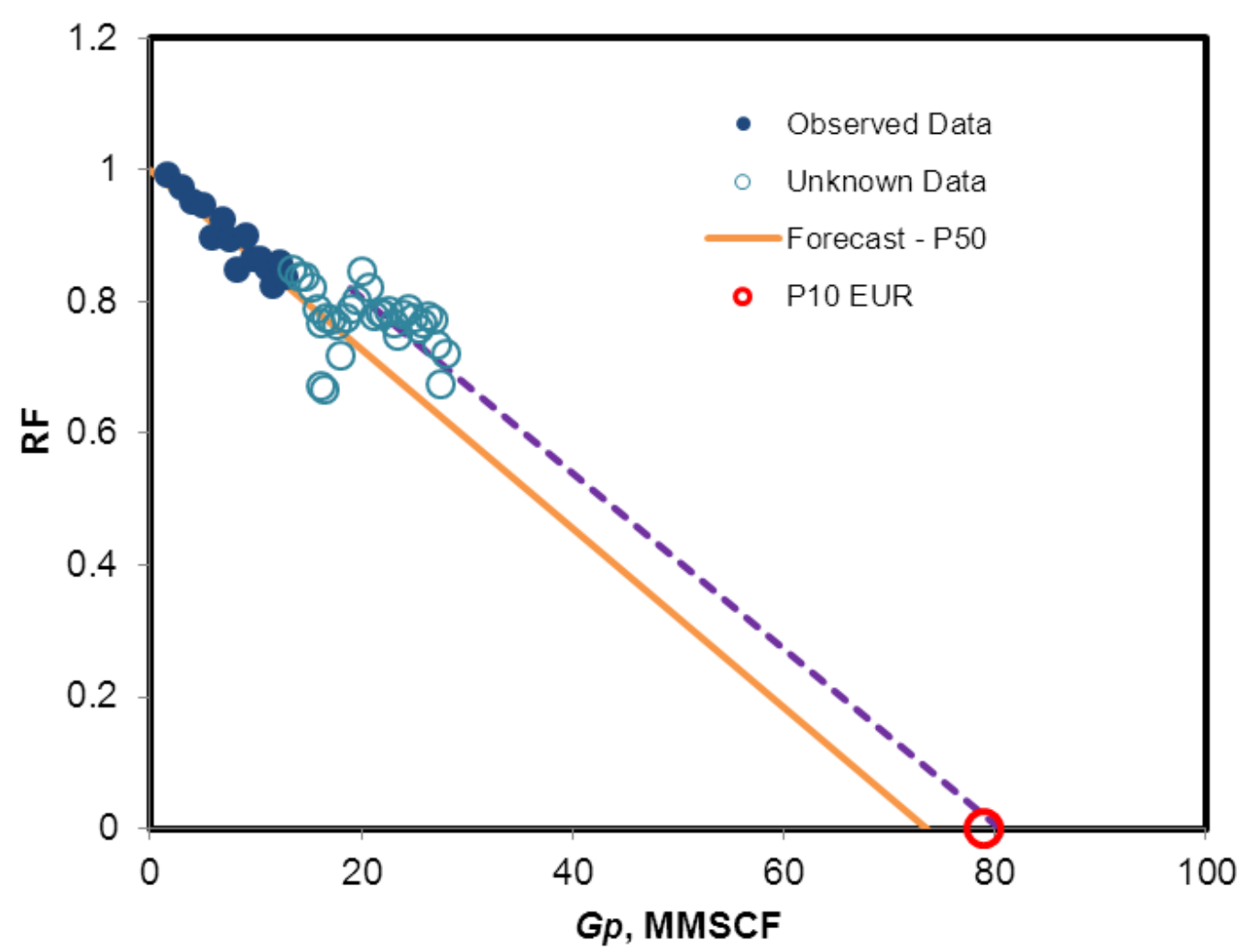

Figure 4.19 - Recovery potential plot of the second field example in Marcellus

Shale.

In order to provide a general view of the analysis of 224 Marcellus Shale wells, we demonstrate actual recoveries and P10-P90 ranges of randomly selected 40 wells in the field in Fig. 4.20. Differences of the P10-P90 intervals are the outcome of different groups. It is fair to say that our methodology is able to capture the actual recovery within the interval most of the cases. 


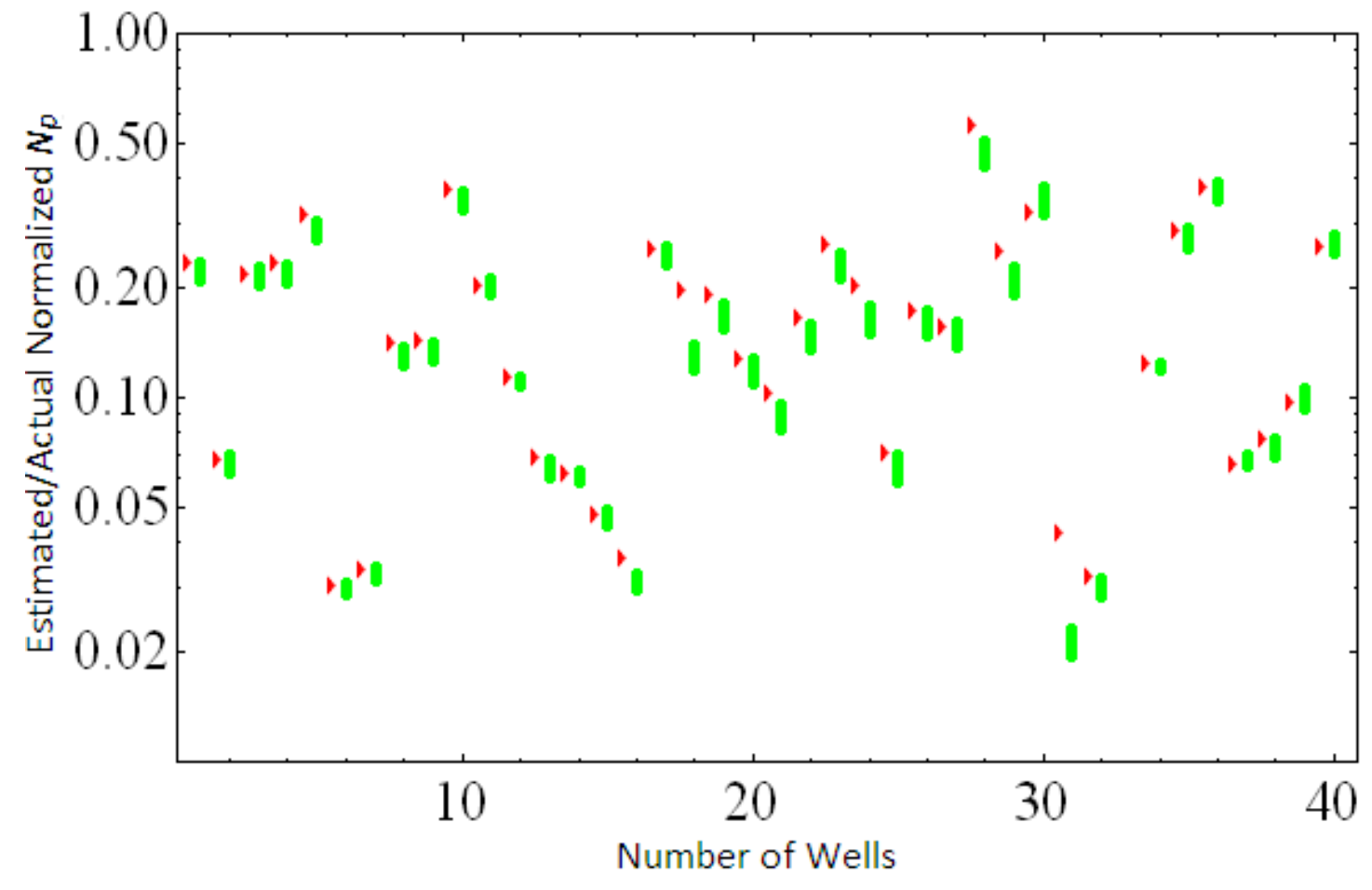

Figure 4.20 - Estimates and actual cumulative production of 40 wells in Marcellus Shale gas play.

\subsubsection{Field Example 3: Elm Coulee Oil Field}

Although the production in Bakken Field of Montana and western North Dakota began in the 1950's, the field is experiencing significant development during the last years due to its tremendous oil accumulation (Tabatabaei, Mack, and Daniels 2009). Horizontal wells with hydraulic fracture treatments are proven effective in this reservoir. Our third field example consists of 400 wells in Elm Coulee field in Bakken reservoir. This example has a specific importance because it will show the performance of the proposed methodology on oil wells. 
Although we examine 400 wells in Elm Coulee field, we did not see a sparse histogram of maximum monthly productions as seen in Fig. 4.21. Similar to Marcellus Shale example, we divide the wells into three groups.

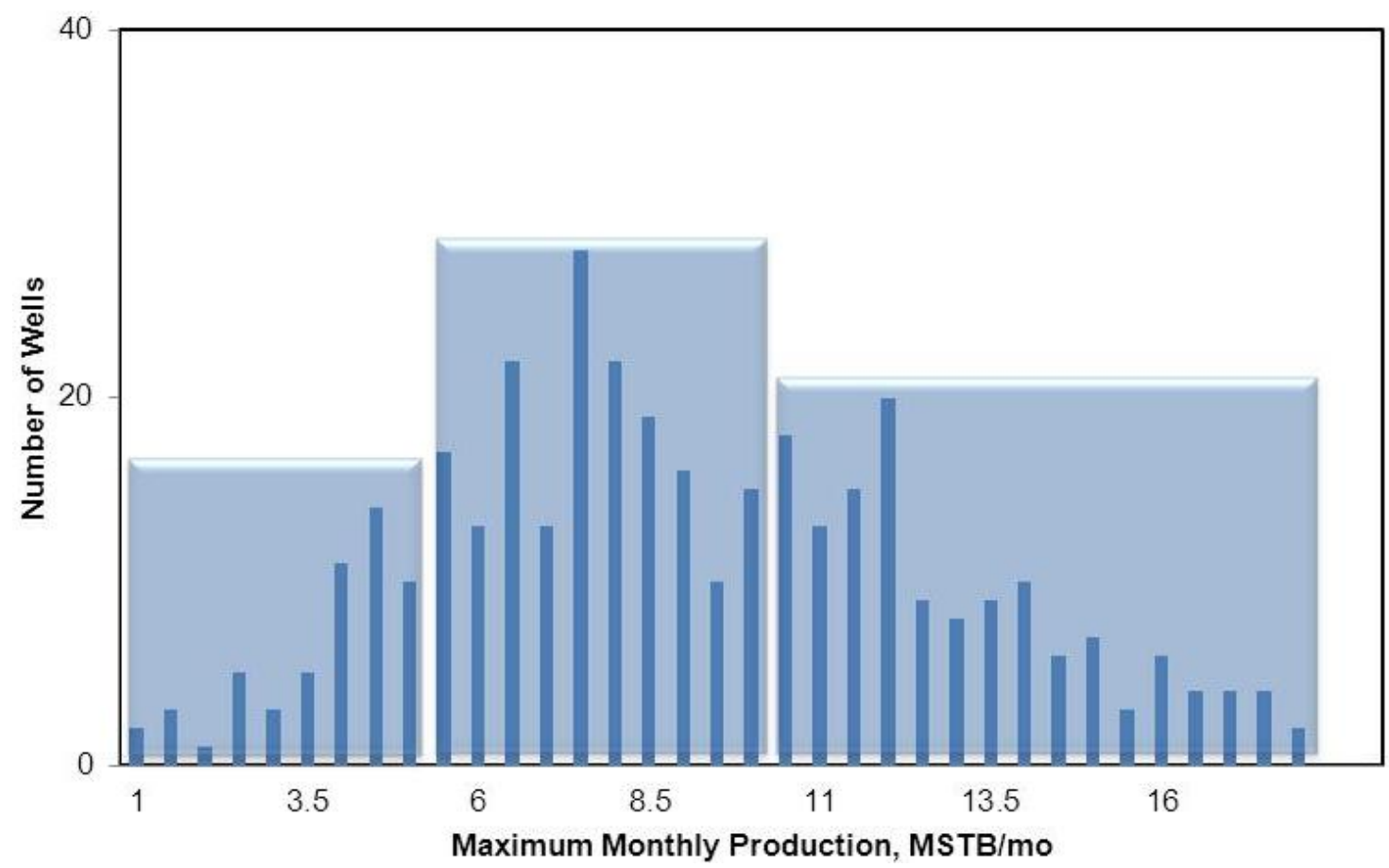

Figure 4.21 - Grouping of Elm Coulee oil field wells based on their peak production.

Fig. 4.22 illustrates the parameter distributions of the groups. Contrary to other field examples, parameters show an ordered behavior. Although $n_{P 90}$ values still remain similar, $n_{P 50}$ and $n_{P 10}$ values of both parameters increases exponentially as peak production increases. This behavior is encouraging for further investigation the nature of the parameters based on groups. 

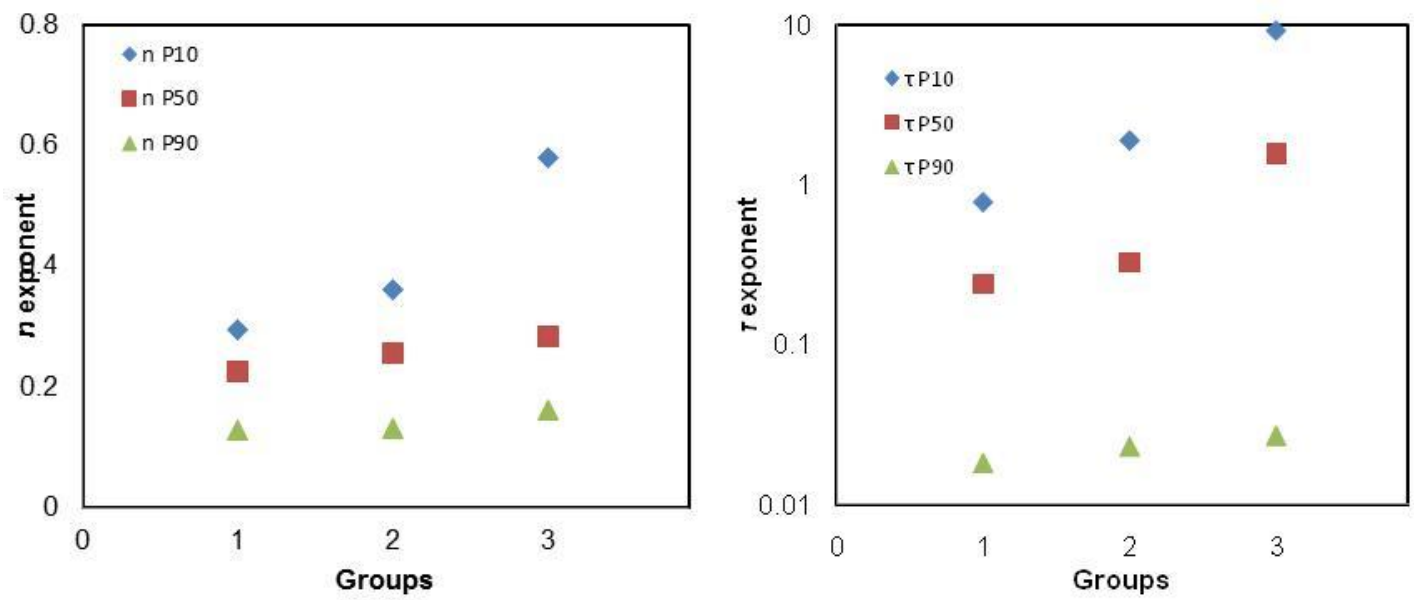

Figure 4.22 - Distribution of $\boldsymbol{n}$ and $\boldsymbol{\tau}$ parameter pairs of EIm Coulee oil field example.

The following example contains production data from a young oil well from the Elm Coulee field. This well has been on production for five years with minimum water production. Visual examination shows that after 40 months of production the well experienced an operation as seen in Fig. 4.23. 


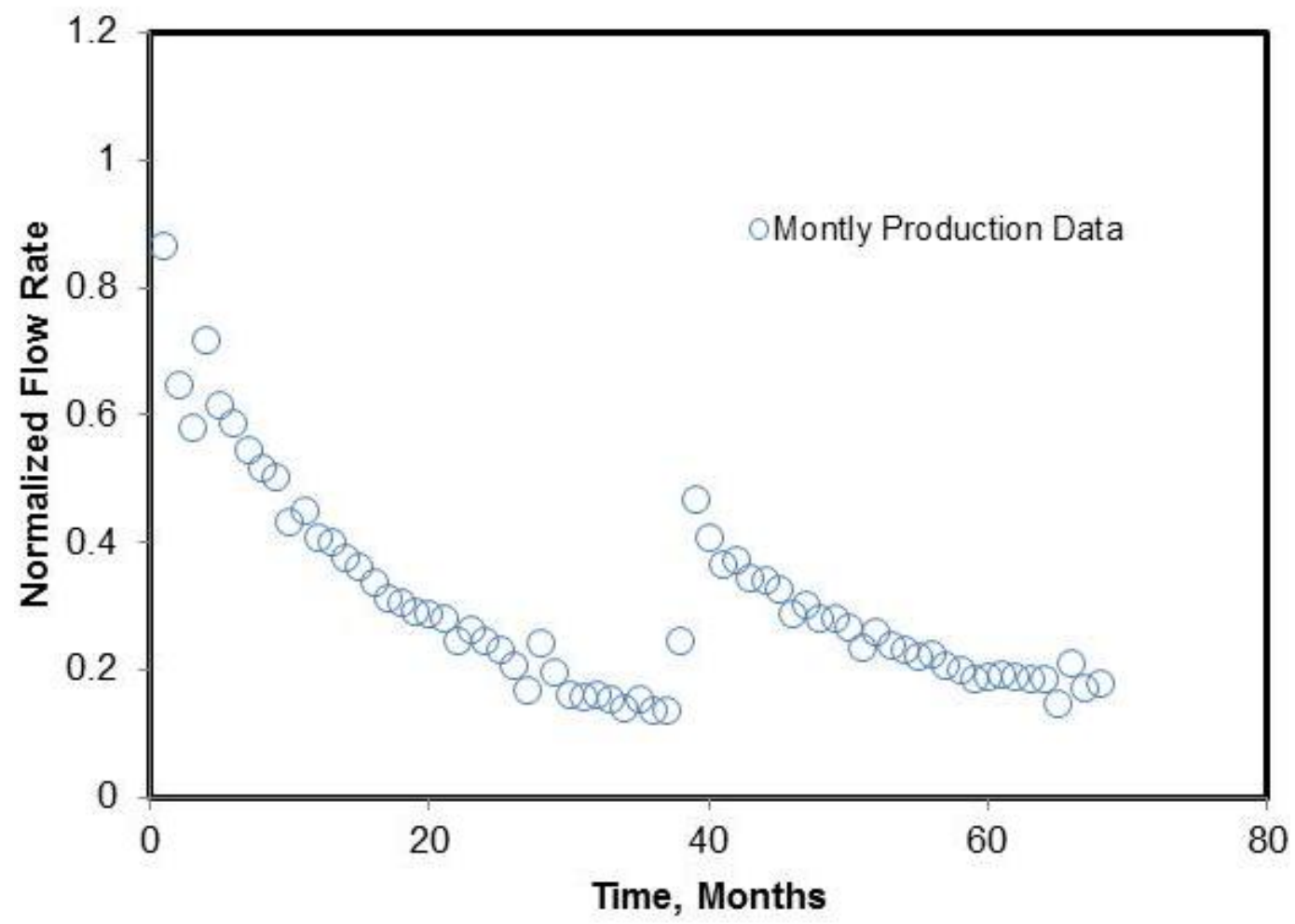

Figure 4.23 - Monthly production history plot for field example of EIm Coulee oil

field.

We analyze the well presuming that the first one and a half year's history is known, as indicated in Fig. 4.24. Production decline follows the P90 trend until the operation takes place which changes the behavior entirely for some time. However after five years decline stabilizes to P10 trend again. 


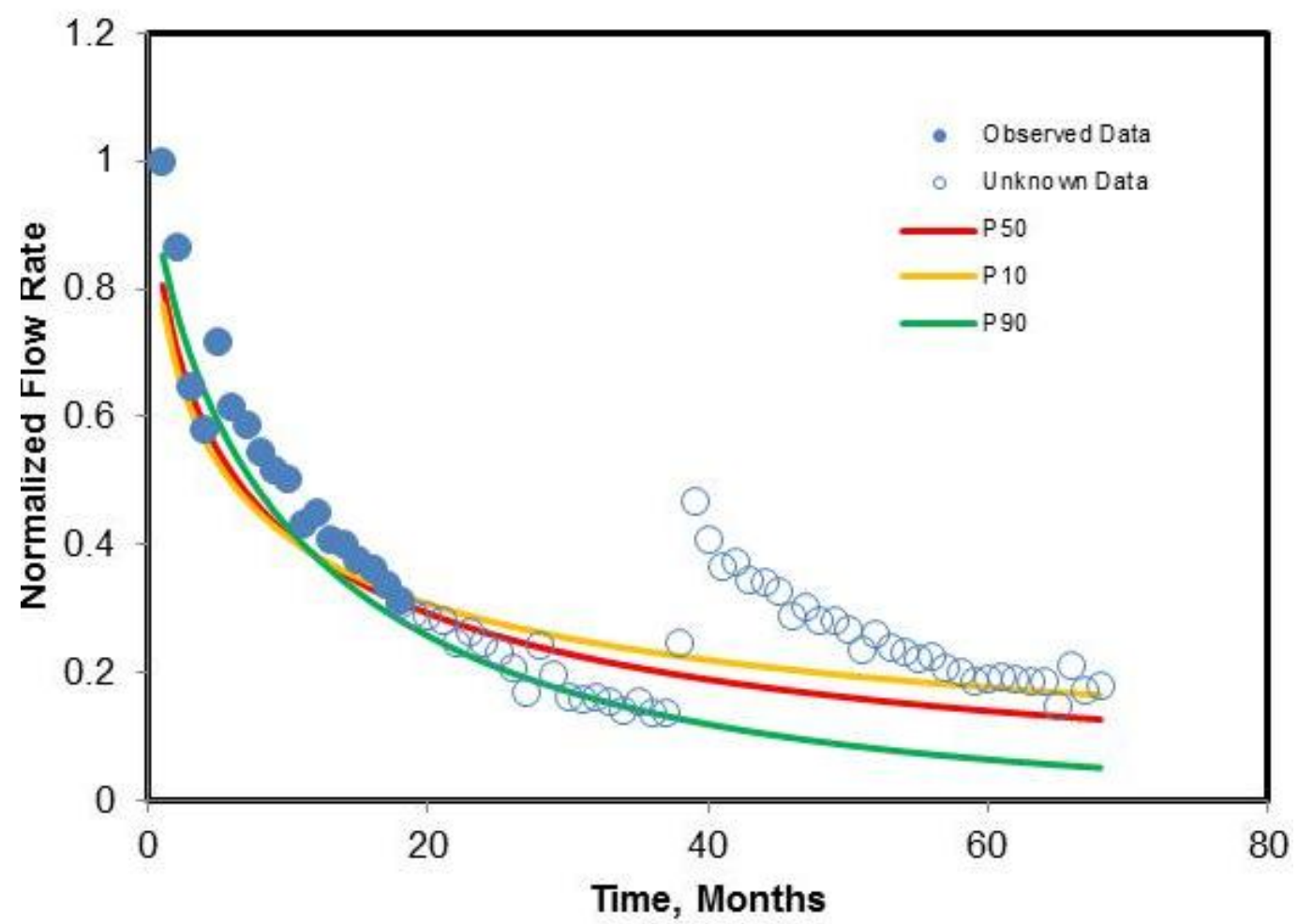

Figure 4.24 - Production forecast of the field example in EIm Coulee oil field.

Recovery potential analysis plot also advises the same suggestion with additional information. From Fig. 4.25, it is revealing that why operator decided to restimulate the well as it is seen that after 90 MSTB production, well entered an unusual decline behavior. Although operation achieved to deliver additional reserves, it did not completely change the decline behavior. 


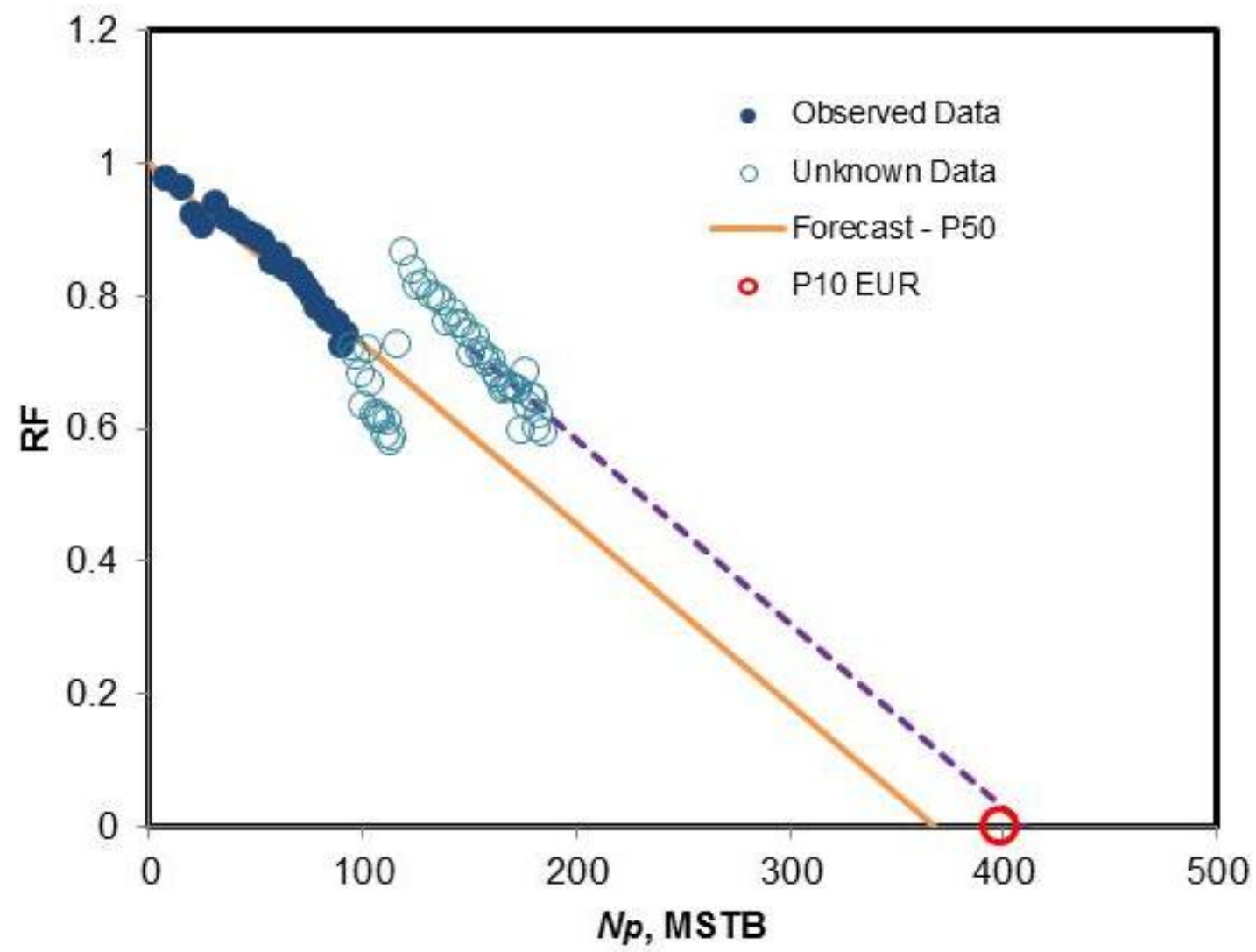

Figure 4.25 - Recovery potential plot of the field example in Elm Coulee oil field.

We examine 400 oil wells in Elm Coulee field of Bakken play and Fig. 4.26 demonstrates the actual recoveries up to most recent time and thier P10-P90 intervals of randomly selected 40 wells. It is worth mentioning that proposed methodology delivers a larger P10-P90 interval in oil wells as we see in synthetic examples. This is due to relatively bigger difference between the parameters within the same group. Another significant result of tight oil field example is that proposed methodology tends to produce pessimistic results for oil wells. 


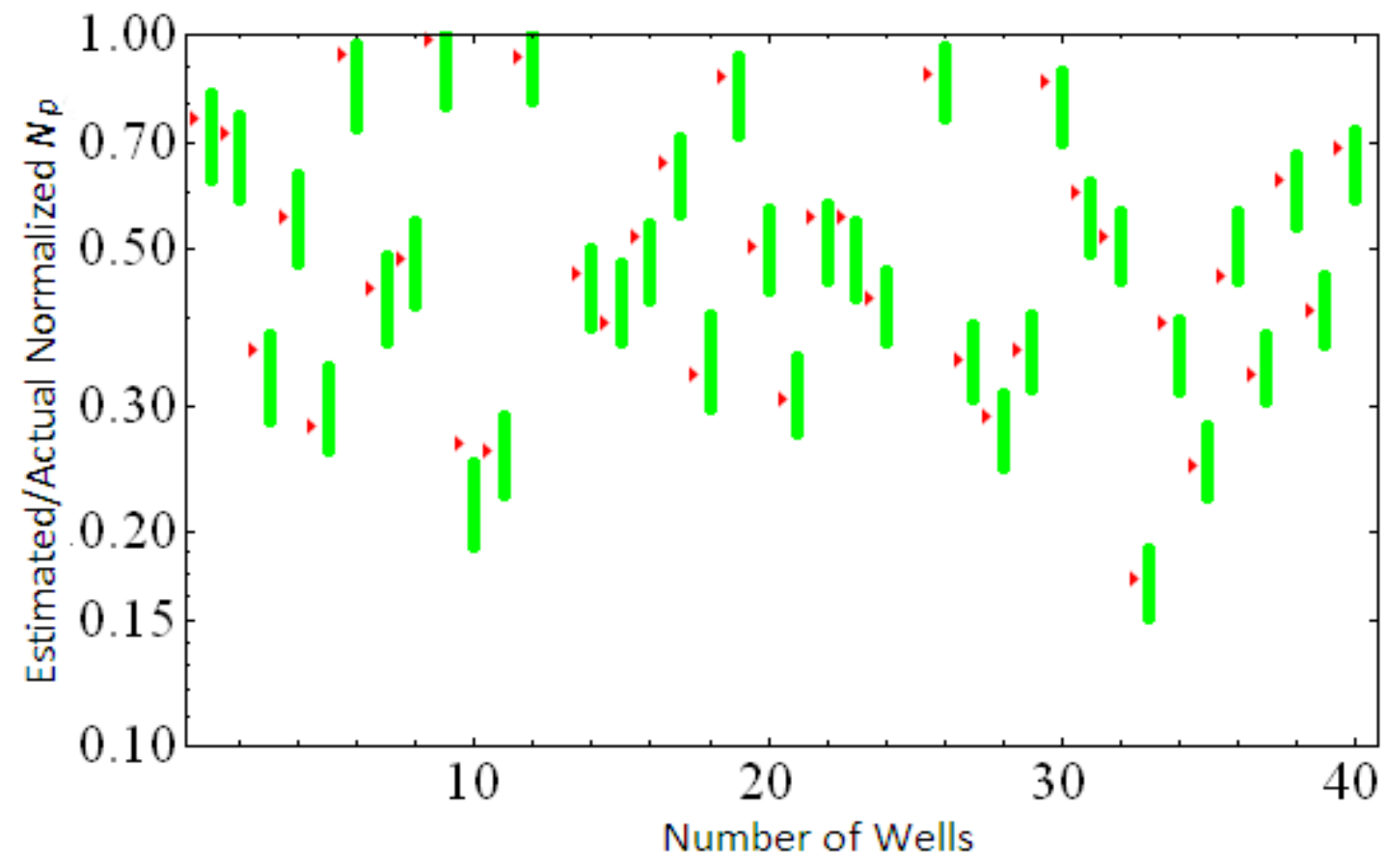

Figure 4.26 - Estimates and actual cumulative production of 40 wells in Elm Coulee oil field.

\subsubsection{Overall Results}

The overall results of the three field cases are shown in Table 4.3. On the average, at least three-fourths of the wells' performance falls within the expected P10/P90 range. Also Table 4.3 confirms the fact that a significant portion of wells falls below P90 trend in oil field cases. Given the uncertainty inherent in raw field data within any database and lack of specific information about a well's condition with time, we consider these results encouraging. 
Table 4.3 - Percentage of wells fall within and outside the P10 - P90 range.

\begin{tabular}{|c|c|c|c|}
\hline & $\begin{array}{c}\text { Within } \\
\text { P10-P90 }(\%)\end{array}$ & $\begin{array}{c}\text { Above P10 } \\
(\%)\end{array}$ & $\begin{array}{c}\text { Below P90 } \\
(\%)\end{array}$ \\
\hline $\begin{array}{c}\text { Barnett Shale } \\
(500 \text { wells })\end{array}$ & 79.7 & 9.5 & 9.8 \\
\hline $\begin{array}{c}\text { Marcellus Shale } \\
(224 \text { wells })\end{array}$ & 74.5 & 12.1 & 13.4 \\
\hline $\begin{array}{c}\text { Elm Coulee, Bakken } \\
\text { Shale (400 wells) }\end{array}$ & 74.4 & 8.5 & 17.1 \\
\hline
\end{tabular}




\section{CHAPTER V}

\section{SUMMARY, CONCLUSIONS, AND RECOMMENDATIONS}

\subsection{Summary}

In this study, we initially examined the various advantages of the stretched-exponential decline model over the Arps' hyperbolic relation when reserves estimation of unconventional reservoirs is attempted. Several studies (e.g., Ilk et al 2008, 2010) have pointed out that the Arps method provides optimistic solutions for unconventional reservoirs because the classical reservoir boundaries are not reached. However, its simplicity, with regard to data fitting, is appealing. In contrast, the SEPD provides a more rational and consistent way of estimating reserves, particularly in a probabilistic frame.

Second, we developed a systematic methodology for analysis and interpretation of production data obtained from individual wells in an unconventional reservoir. This methodology provides a probabilistic reserves estimation framework for any large production dataset. The proposed methodology yields consistent solutions with the simulated results for both the gas and oil wells. Similarly, three independent field data sets verified that the approach is reliable as the P10/P90 index tool.

Any simple predictive tool presupposes that intrinsic well condition does not change in a well's producing life. However, in practice this ideal condition is often violated. Restimulation of fractures and installation of artificial-lift systems in oil wells are cases in point. In gas wells, periodic wellbore dewatering changes the boundary condition. Although not stated explicitly, all decline-curve methods presume constant-pressure 
production. If such conditions are not met, changes in pressures and rate need monitoring to do conventional rate-transient and transient-PI analyses.

\subsection{Conclusions}

- The stretched-exponential decline model (SEPD) is superior to Arps' hyperbolic relation with regard to estimation of reserves in unconventional reservoirs. The SEPD's advantage owes largely to its bounded nature and the linear behavior of the recovery potential analysis. Bounded nature of the model prevents a potential overestimation of reserves which is very likely in Arps' hyperbolic relation when longer time frames are used. Recovery potential analysis of the model offers a better understanding on EUR, also acts like a secondary diagnosis analysis plot which improves the examination of the changes in decline trends.

- The results of 54 synthetic and 1124 field data sets from three different shale types show that the suggested methodology gives reliable production forecasts, as well as EUR estimations for both the gas and oil wells in an unconventional setting. This method attains the desired results $75 \%$ of the time. Although oil field examples yield to more pessimistic results than gas field cases, the results are still in acceptable ranges.

- The ability to treat large databases by well grouping gives realistic statistical distributions of SEPD parameters. It is worth mentioning that well grouping does not offer the desired objective to group wells based on their similar behavior. Although grouping wells should be based on their similar decline trends, peak production histogram approach is far from representing this circumstance. In our 
methodology, grouping wells based on their peak productions allows us to offer smaller P10-P90 interval.

- Overall, the mathematical insights into the SEPD provide an opportunity to understand the decline behavior in unconventional reservoirs.

\subsection{Recommendations}

We recommend the following for future research.

- To analyze the SEPD model parameters in terms of identifying a characteristic behavior for the wells producing from the same field. Our results indicate that $n$ exponent does not change dramatically in the same field. Future efforts can focus on the behavior of $n$ exponent in large datasets.

- To develop new techniques for grouping wells in terms of similar decline behaviors. For example, instead of peak production, steepness of the decline may offer a better approach to well grouping.

- To investigate the probabilistic future performance interval (P10/P90) of numerical flow simulations and compare to the proposed methodology. 


\section{NOMENCLATURE}

\section{Variables:}

$a=$ Flow rate ratio (Eq. 2.26), dimensionless

$a=$ Model parameter (Eqs. 2.12, 2.13, 2.17, 2.18), dimensionless

$b \quad=\quad$ Arps' decline exponent, dimensionless

$b \quad=\quad$ Model parameter (Eq. 2.25), $D^{-1}$

$c \quad=$ Extreme-C constant, dimensionless

$c \quad=\quad$ Model parameter (Eqs. 2.6, 2.7, 2.8, 2.10, 2.13), dimensionless

$D \quad=\quad$ Reciprocal of loss ratio, $D^{-1}$

$D_{1}=$ Model parameter (Eq. 2.16), $D^{-1}$

$D_{i} \quad=\quad$ Initial decline constant for exponential and hyperbolic rate relation, $D^{-1}$

$D_{\infty} \quad=\quad$ Model parameter (Eq. 2.16), $D^{-1}$

$E U R=$ Estimated ultimate recovery, SCF or STB

$F_{c} \quad=$ Fracture conductivity, md-ft

$G \quad=$ Original (contacted) gas-in-place, $\mathrm{SCF}$

$G_{p} \quad=$ Cumulative gas production, $\mathrm{SCF}$

$h=$ Formation thickness, $\mathrm{ft}$

$h \quad=\quad$ Model parameter (Eqs. 2.19), dimensionless

$k=$ Formation permeability, md

$L_{w} \quad=\quad$ Horizontal well length, $\mathrm{ft}$

$m \quad=\quad$ Model parameter (Eqs. 2.6, 2.7, 2.8), dimensionless

$N_{F S}=$ Number of fractures, dimensionless 


$$
\begin{array}{ll}
N_{p} & =\text { Cumulative oil production, STB } \\
N_{p, \infty} & =\text { Cumulative oil production at infinite time, STB } \\
n & =\text { Exponent parameter of SEPD model, dimensionless } \\
p & =\text { Pressure, psi } \\
p_{i} & =\text { Initial reservoir pressure, psi } \\
p_{w f} & =\text { Flowing bottomhole pressure, psi } \\
q & =\text { Production rate, SCF/D or STB/D } \\
q_{i} & =\text { Initial production rate, SCF/D or STB/D } \\
q_{0} & =\text { Parameter of production decline models, SCF/month or STB/month } \\
r p & =\text { Recovery potential, dimensionless } \\
t & =\text { Production time, days } \\
t & =\text { Production time, days } \\
x_{f} & =\text { Fracture half-length, ft } \\
& =\text { Gas compressibility factor, dimensionless }
\end{array}
$$

Greek Symbols:

$\gamma \quad=\quad$ Model parameter (Eqs. 2.9), dimensionless

$\tau=$ Characteristic time parameter for SEPD model, month

$\Gamma \quad=$ Euler Gamma function 


\section{REFERENCES}

Agbi, B. and Ng, M.C. 1987. A Numerical Solution to Two-Parameter Representation of Production Decline Curve Analysis. Paper presented at the Petroleum Industry Application of Microcomputers, Lake Conroe, Texas. 1987, Society of Petroleum Engineers 16505-MS.

Arps, J.J. 1945. Analysis of Decline Curves. Paper presented at the AIME Houston Meeting, Houston, Texas. 1944. 945228-G.

Arthur, J.D., Bohm, B.K., Coughlin, B.J. et al. 2009. Evaluating the Environmental Implications of Hydraulic Fracturing in Shale Gas Reservoirs. Paper presented at the SPE Americas E\&P Environmental and Safety Conference, San Antonio, Texas. 121038.

Behrenbruch, P., Turner, G.J., and Backhouse, A.R. 1985. Probabilistic Hydrocarbon Reserves Estimation: A Novel Monte Carlo Approach. Paper presented at the Offshore Europe, Aberdeen, United Kingdom. 1985 Society of Petroleum Engineers of AIME 13982-MS.

Blasingame, T.A. and Rushing, J.A. 2005. A Production-Based Method for Direct Estimation of Gas in Place and Reserves. Paper presented at the SPE Eastern Regional Meeting, Morgantown, West Virginia. Society of Petroleum Engineers 98042-MS.

Chen, Z. 1991. A Detecting Technique for Production Rate Decline-Curve Analysis with Residual Plots. Paper presented at the Petroleum Computer Conference, Dallas, Texas. 1991, Society of Petroleum Engineers, Inc. 22313-MS.

Cheng, Y., Wang, Y., McVay, D.A. et al. 2005. Practical Application of Probabilistic Approach to Estimate Reserves Using Production-Decline Data. Paper presented at the SPE Annual Technical Conference and Exhibition, Dallas, Texas. Society of Petroleum Engineers 95974-MS.

Fetkovich, M.J. 1980. Decline Curve Analysis Using Type Curves. SPE Journal of Petroleum Technology 32 (6): 1065-1077. 4629-PA.

Fetkovich, M.J., Vienot, M.E., Bradley, M.D. et al. 1987. Decline Curve Analysis Using Type Curves: Case Histories. SPE Formation Evaluation 2 (4): 637-656. 13169PA.

Gentry, R.W. 1972. Decline-Curve Analysis. SPE Journal of Petroleum Technology 24 (1). 3356-MS. 
Gentry, R.W. and McCray, A.W. 1978. The Effect of Reservoir and Fluid Properties on Production Decline Curves. SPE Journal of Petroleum Technology 30 (9). 6341.

Gross, H.E. 1939. Decline-Curve Analysis. Paper presented at the AIME San Antonio Meeting, San Antonio, Texas. 1938. 939101-G.

Halton, J.H. 1970. A Retrospective and Prospective Survey of the Monte Carlo Method. SIAM Review 12 (1): 1-63.

Hefner, J.M. and Thompson, R.S. 1996. A Comparison of Probabilistic and Deterministic Reserve Estimates: A Case Study (Includes Associated Paper 36358 ). SPE Reservoir Engineering 11 (1): 43-47. 26388-PA.

Higgins, R.V. and Lechtenberg, H.J. 1969. Merits of Decline Equations Based on Production History of 90 Reservoirs. Paper presented at the SPE Rocky Mountain Regional Meeting, Denver, Colorado. 1969, American Institute of Mining, Metallurgical and Petroleum Engineers Inc. 2450-MS.

Huffman, C.H. and Thompson, R.S. 1994. Probability Ranges for Reserve Estimates from Decline Curve Analysis. Paper presented at the SPE Annual Technical Conference and Exhibition, New Orleans, Louisiana. 1994 Society of Petroleum Engineers 28333-MS.

Idrobo, E.A., Jimenez, E.A., and Bernal, M.C. 2001. A New Tool to Make Quick Estimates of Probabilistic Reserves from Production Trends. Paper presented at the SPE Hydrocarbon Economics and Evaluation Symposium, Dallas, Texas. Society of Petroleum Engineers Inc. 68597-MS.

Ilk, D., Currie, S.M., Symmons, D. et al. 2010. Hybrid Rate-Decline Models for the Analysis of Production Performance in Unconventional Reservoirs. Paper presented at the SPE Annual Technical Conference and Exhibition, Florence, Italy. Society of Petroleum Engineers 135616-MS.

Ilk, D., Rushing, J.A., Perego, A.D. et al. 2008. Exponential vs. Hyperbolic Decline in Tight Gas Sands: Understanding the Origin and Implications for Reserve Estimates Using Arps' Decline Curves. Paper presented at the SPE Annual Technical Conference and Exhibition, Denver, Colorado. Society of Petroleum Engineers 116731-MS.

Jochen, V.A. and Spivey, J.P. 1996. Probabilistic Reserves Estimation Using Decline Curve Analysis with the Bootstrap Method. Paper presented at the SPE Annual Technical Conference and Exhibition, Denver, Colorado. 1996, Society of Petroleum Engineers, Inc. 36633-MS. 
Johnson, R.H. and Bollens, A.L. 1927. The Loss Ratio Method of Extrapolating Oil Well Decline Curves. Paper presented at the AIME New York Meeting, New York, New York. 1928. 927771-G.

Johnston, D.C. 2006. Stretched Exponential Relaxation Arising From a Continuous Sum of Exponential Decays. Phys. Rev. B 74: 184430.

Kohlrausch, R., 1847, Nachtrag Uber die Elastische Nachwirkung Beim Cocon und Glasladen, Pogg Ann. Physik 72 (3). 353 -405.

Lewis, J.O. and Beal, C.H. 1918. Some New Methods for Estimating the Future Production of Oil Wells. Paper presented at the AIME New York Meeting, New York, New York. 1918. 918492-G.

Long, D.R. and Davis, M.J. 1988. A New Approach to the Hyperbolic Curve (Includes Associated Papers 18728 and 18942 ). SPE Journal of Petroleum Technology 40 (7). 16237.

Maley, S. 1985. The Use of Conventional Decline Curve Analysis in Tight Gas Well Applications. Paper presented at the SPE/DOE Low Permeability Gas Reservoirs Symposium, Denver, Colorado. 1985, Society of Petroleum Engineers 13898MS.

Matthews, C.S. and Lefkovits, H.C. 1956. Gravity Drainage Performance of DepletionType Reservoirs in the Stripper Stage. 665-G-P.

Metropolis, N.C. and Ulam, S.M. 1919. The Monte-Carlo Method. J. Amer. Stat. Assoc., 44: 335-341.

McNulty, R.R. and Knapp, R.M. 1981. Statistical Decline Curve Analysis. Paper presented at the SPE Annual Technical Conference and Exhibition, San Antonio, Texas. 1981, Society of Petroleum Engineers of AIME 10279-MS.

Mead, H.N. 1956. Modifications to Decline Curve Analysis. AIME Petroleum Transactions 207 (1). 11-16. 464-G.

Murtha, J.A. 1994. Incorporating Historical Data into Monte Carlo Simulation. SPE Computer Applications 6 (2). 26245.

Patricelli, J.A. and McMichael, C.L. 1995. An Integrated Deterministic/Probabilistic Approach to Reserve Estimations(Includes Associated Papers 31056 and 35248 ). SPE Journal of Petroleum Technology 47 (1). 28329. 
Reyes, J.L.P., Li, K., and Horne, R.N. 2004. Application of a New Mechanistic Decline Curve Method to Kern County Oil Fields. Paper presented at the SPE Annual Technical Conference and Exhibition, Houston, Texas. Society of Petroleum Engineers 90212-MS.

Risso, F.V.A., Risso, V.F., and Schiozer, D.J. 2007. Risk Assessment of Oil Fields Using Proxy Models: A Case Study. Paper presented at the Canadian International Petroleum Conference, Calgary, Alberta. 2007-138.

Shea, G.B. and Higgins, R.V. 1964. Decline and Forecast Studies Based on Performances of Selected California Oilfields. SPE Journal of Petroleum Technology 16 (9). 833.

Shirman, E.I. 1999. Universal Approach to the Decline Curve Analysis. Journal of Canadian Petroleum Technology 38 (13). 99-13-68.

Slider, H.C. 1968. A Simplified Method of Hyperbolic Decline Curve Analysis. SPE Journal of Petroleum Technology 20 (3). 1936.

Spivey, J.P., Jr., J.H.F., Williamson, J.R. et al. 2001. Applications of the Transient Hyperbolic Exponent. Paper presented at the SPE Rocky Mountain Petroleum Technology Conference, Keystone, Colorado. Society of Petroleum Engineers 71038-MS.

Stewart, P.R. 1970. Low-Permeability Gas Well Performance at Constant Pressure. SPE Journal of Petroleum Technology 22 (9). 2604.

Stright Jr., D.H. and Gordon, J.I. 1983. Decline Curve Analysis in Fractured Low Permeability Gas Wells in the Piceance Basin. Paper presented at the SPE/DOE Low Permeability Gas Reservoirs Symposium, Denver, Colorado. 1983 Society of Petroleum Engineers of AIME 11640-MS.

Tabatabaei, M., Mack, D.J., and Daniels, N.R. 2009. Evaluating the Performance of Hydraulically Fractured Horizontal Wells in the Bakken Shale Play. Paper presented at the SPE Rocky Mountain Petroleum Technology Conference, Denver, Colorado. 122570.

Valko, P.P. 2009. Assigning Value to Stimulation in the Barnett Shale: A Simultaneous Analysis of 7000 Plus Production Hystories and Well Completion Records. Paper presented at the SPE Hydraulic Fracturing Technology Conference, The Woodlands, Texas. Society of Petroleum Engineers 119369-MS.

Valko, P.P. and Lee, W.J. 2010. A Better Way to Forecast Production from Unconventional Gas Wells. Paper presented at the SPE Annual Technical 
Conference and Exhibition, Florence, Italy. Society of Petroleum Engineers 134231-MS. 


\section{VITA}

Name:

Bunyamin Can

Born:

Samsun, Turkey

Address:

Texas A\&M University

Department of Petroleum Engineering

3116 TAMU 501 RICH

College Station, Texas 77843-3116

E-mail Address:

bunyamincan@msn.com

Education:

Texas A\&M University, College Station, Texas, USA

Master of Science Degree in Petroleum Engineering

May 2011

Istanbul Technical University, Istanbul, Turkey

Bachelor of Science Degree in Petroleum Engineering

January 2009

Affiliations:

Society of Petroleum Engineers 